\title{
Decisive Role of Polymer-BSA Interactions in Biofilm Substrates on 'Philicity' and EPS Composition
}

Suparna Dutta Sinha', Madhumita Choudhuri², Tania Basu³ ${ }^{3}$ Debkishore Gupta ${ }^{4}$ and Alokmay Datta $^{5}$

${ }^{1}$ College of Engineering, Mathematics \& Physical Sciences, Living Systems Institute, University of Exeter, Cornwall EX4 4QD, United Kingdom

${ }^{2}$ School of Nanoscience and Technology, Indian Institute of Technology, Kharagpur 721 302, India

${ }_{3}^{3}$ Condensed Matter Physics Research Centre, Jadavpur University, Kolkata 700 032, India

${ }^{4}$ Department of Microbiology, CK Birla Hospitals, Kolkata 700027, India

${ }^{5 X R D}$ and SEM Units, Materials Characterization and Instrumentation Division, CSIR-Central Glass and Ceramic Research Institute, Kolkata 700 032, India

\begin{abstract}
Formation of extracellular polymeric substances (EPS) is a crucial step for bacterial biofilm growth. Dependence of EPS composition on the growth substrate and the conditioning of the latter is thus of primary importance. Here, we present results of studies on the growth of biofilms of two different strains each, of the Gram negative bacteria Escherichia coli and Klebsiella pneumoniae, on four polymers used commonly in indwelling medical devices - Polyethene, Polypropylene, Polycarbonate, and Polytetrafluoroethylene immersed in Bovine Serum Albumin (BSA) for 24 hrs. The polymer substrates are studied before and after immersing in BSA for 9 hrs and 24 hrs, using contact angle measurement (CAM) and Field Emission Scanning Electron Microscopy (FE-SEM) to extract, respectively, the 'philicity' (defined as $\phi \equiv \sin \left(\theta-90^{\circ}\right)$, where $\theta$ is contact angle of the liquid on the solid at a particular temperature and ambient pressure) and spatial Hirsch parameter $H$ (defined from the relation, $F(r) \sim r^{2 H}$, where $F(r)$ is the mean squared density fluctuation at the sample surface). $H=$, $<0.5$ or $>0.5$ signifies no correlation, anti-correlation, and correlation, respectively. The substrates are seen to transform from large hydrophobicity to near amphiphilicity with the formation of BSA conditioning surface layer, and the $H$-values distinguish the length scales of $\sim 100 \mathrm{~nm}$, $500 \mathrm{~nm}$, and $2000 \mathrm{~nm}$, with the anti-correlation increasing with length scale. Biofilms grown on the BSA-covered surfaces are studied with CAM, FE-SEM, Fourier Transform Infrared (FTIR) and Surface Enhanced Raman Spectroscopy (SERS). Most notably, the $\phi$-values are independent of the bacterial species and strain but dependent on the polymer, as is also shown strikingly by both types of spectra, while $H$-values show some bacterial variation. Thus, the EPS composition and consequently the wetting properties of the corresponding bacterial biofilms seems to be decided by the interaction of the conditioning BSA layer with a specific polymer used as the growth substrate.
\end{abstract}




\section{Introduction}

Biofilms form the collective mode of existence of bacteria apart from the isolated or planktonic mode. Though they were detected by Leeuwenhoek in the earliest instance of microscopy, basic understanding about biofilms, especially their striking levels of organization and properties, has emerged only recently [1-3]. On one hand, they have proved to be highly beneficial in providing sustenance in both land and aquatic environments by maintaining the bacterial population networks at soil and water surfaces [4-7]. On the other hand, they pose grave medical threats, by forming pathogen organizations within the physiological environment on indwelling medical devices and biomaterial implants [8-11], which form a significant part of healthcare associated infection worldwide [12-14]. Biofilms in clinical samples, which have been much less presented outside dental plaques, are always found to develop attached to a surface unless dislodged from the site of infection [15]. Hence, the specifics of the surface structure and compositions are some of the key determinants of biofilm growth and development as they decide the bacteria-surface forces.

Bacteria organize themselves into biofilms through the formation of extra-cellular polymeric substance or EPS [16]. This is highly heterogeneous and poorly defined [17], with polysaccharides as a primary/base constituent accompanied with a variety of proteins, lipids [18,19], and smaller organic molecules serving different functions in the biofilm. The composition of EPS is known to vary among biofilms of different bacterial species, and maybe even among biofilms of the same species under different growth conditions [20,21]. The composition of EPS is known to decide the functionality of the biofilm; hence the control of this composition can effectively control its pathogenic activity $[\mathbf{2 2}, \mathbf{2 3}]$. However, what is most important is that in the absence of the EPS or in the event of its composition being suitably changed, biofilm growth itself may be stopped. The indepth knowledge about the contribution of albumin in surface modification of biomaterials and the manner in which the biofilm bacteria respond to it through substrate-specific variation of the chemical constituents of the EPS matrices will not only enhance the knowledge of the initial stages of biofilm formation on medical devices, but will also be crucial in developing non-invasive strategies of biofilm control.

Indwelling medical devices are in general composed of a few common polymers such as Polyethene, especially high density polyethene or HDPE (in knee and hip implants), Polypropylene or PP, Polycarbonate or PC, and Polytetrafluoroethylene or PTFE. Major reasons for using these polymers are their hydrophobicity, high degree of chemical inertness and mechanical strength and lightness (especially in case of HDPE). However, the devices in contact with physiological fluids, tend to get adsorbed with the proteins from plasma and other body fluids within nanoseconds of its introduction $[24,25]$, much before the arrival of the microbes or tissue cells. Hence the pathogens and the surrounding tissue cells, which appear at the site of introduction of the medical devicemuch later, view the 'surface with the adsorbed protein layer' as the 'original foreign surface' instead of it being only a 'conditioning layer' [26]. This conditioning layer, especially albumin has the propensity to alter the hydrophobicity and chemical sterility [27] of the surface of the medical devices in a manner that may finally lead to septicaemia or irreversible device-associated infections through the formation of biofilms. Since biofilms exhibit very low susceptibility to antibiotics, it is 
imperative to understand the manner in which albumin modulates the polymer surfaces to enhance of biofilm growth.

In this communication, we present the results of our investigations regarding two issues, in two separate sections - Part I: how the interaction between serum albumin and the polymers mentioned above may change the surface property, specifically the wetting property of the polymer biomaterials, and Part II: how the interactions between these modified surfaces and the major organic components of biofilms grown on them change the wetting property and, more important, the composition of the EPS. Instead of HSA we have used the more standardised and reproducible bovine serum albumin (BSA) with essentially the same composition. Clinical and American Type Culture Collection or ATCC strains of Gram-negative bacteria Escherichia coli or E. coli (EC and EA respectively) and Klebsiella pneumoniae or K. pneumoniae (KC and KA respectively) were used as the biofilm forming bacteria. We have found that (1) while BSA-polymer interactions vary from polymer to polymer, the trend is to reduce the hydrophobicity to a value where the surface can be wetted by water (or other hydrophilic substances) as well as by hydrocarbons (or other hydrophobic substances), i.e. modulation of the hydrophobic substrates to amphiphilic substrates and (2) these amphiphilic substrates give rise to EPS that vary in composition from polymer to polymer but very similar to each other for the different bacterial strains used.

\section{Part I: Bovine Serum Albumin-coated Polymer Substrates 2.1 Materials and Methods}

\subsubsection{Adsorption of BSA on Polymer samples}

PP is used in a variety of catheters except urinary catheters, while HDPE is widely used in orthopedic implants. The PTFE balloon catheter is especially designed for short- and medium-term urinary drainage, while other catheters are often lined with PTFE to reduce friction and to ensure that other devices can pass through with ease. PC is widely used in indwelling medical devices, where there is a requirement of toughness, rigidity and visual clarity, including minimally invasive surgical devices. Hence the above widely used polymers have been used in our experiments as substrates for growing biofilms.

Commercially available clinical grade (biocompatible) PP, HDPE, PTFE and PC chips having machined finish were obtained in square configuration (10 $\mathrm{mm} \mathrm{X} 10 \mathrm{~mm}$ ) from Plastic Abhiyanta Ltd, India. The water used in all stages of our experiments was of HPLC grade (Lichrosolv) from Merck, India. Tris buffer was obtained from Sigma-Aldrich, USA while BSA was from MP Biomedical Ltd, USA. The polymers chips were initially cleaned in an ultrasonic cleaner, rinsed with water, blow dried, and preserved in a vacuum desiccator, ready for carrying out adsorption [28]. BSA was mixed in the proportion $0.5 \mathrm{mg} / \mathrm{ml}$ with buffer solutions of $\mathrm{pH} 7.4$ and left for a week with intermittent mixing to dissolve the BSA completely. BSA solutions were taken in four sets of separate glass vials, each containing a single chip of each category (PP, PC, PTFE and HDPE) for 9 hrs. The similar procedure of adsorption was repeated for a fresh set of polymer chips, for 24 hours. This stage was conducted in triplicate for both cases. The BSA was left to adsorb on the polymer 
samples for a certain period of time (9 hours and 24 hours), to simulate a static situation, where a biomaterial placed in a physiological environment gets adsorbed with plasma proteins. This time is hence referred to as the 'adsorption time'. After the stipulated period, the chips were removed from the protein solutions, rinsed with water, and finally blow-dried and preserved in a desiccator ready for growing biofilms. The chips obtained, possessed different amounts of BSA adsorbed on them, termed as the 'conditioning layer'. They could not be sterilized further, to prevent the denaturation of the adsorbed protein and were preserved for growing biofilms on them.

\subsubsection{Contact Angle Measurement (CAM)}

The contact angles of water on the different polymers with and without the 'conditioning layer' of adsorbed BSA (for 9 hours and 24 hours) were measured using, static sessile drop method [29]. The angle formed between the solid and the liquid interface was measured using a microscope optical system for capturing and Image J was used to determine the contact angle. All contact angle observations were performed in triplicate. [See SI]

\subsubsection{Field Emission-Scanning Electron Microscopy (FE-SEM)}

The dried polymer chips with and without different proportions of 'conditioning layer' were sputter-coated with a 3-nm-thick conductive layer of gold. FE-SEM measurements were conducted on them, at 2.0-10 kV with a Inspect F5o Microscope (FEI Europe BV, and The Netherlands; FP 2031/12, SE Detector R580). We have used Image J again for analysis of the FE-SEM images.

\subsubsection{Philicity and Hirsch Parameter}

Philicity: We introduce a term 'philicity' to quantify the wetting characteristics of a surface by a liquid. We define it as $\phi \equiv \sin \left(\theta-90^{\circ}\right)$, where $\theta$ is contact angle of the liquid on the solid at a particular temperature and ambient pressure. For water, $\phi<0$ implies the substrate to be hydrophilic, $\phi>0$ means it is hydrophobic, while $\phi=0$ stands for a substrate that is neither and maybe termed 'amphiphilic'.

Hirsch Parameter: The FE-SEM images of the samples yield the mean square intensity fluctuations at different length scales. This spatial variation of intensity along a typical line in each of the observed images can be assumed to follow the spatial variation of sample density under observation. The mean square (ms) intensity fluctuation [30], $F(r), r$ being the separation between points along typical lines, is given by

$$
F(r)=\left\langle[\Delta I(r)-\langle\Delta I(r)\rangle]^{2}\right\rangle
$$

where $I$ is image intensity at point $(x, y), \Delta I(r)=I(x, y)-I\left(x_{0}, y_{0}\right)$, where $\left(x_{0}, y_{0}\right)$ is the reference point and $r=\sqrt{\left(x-x_{0}\right)^{2}+\left(y-y_{0}\right)^{2}} . F(r)$ thus represents the mean squared density fluctuation at the sample surface.

The spatial Hirsch parameter $H$ is defined from the relation, $F(r) \sim r^{2 H}$. This Hirsch parameter divides any spatial pattern into three groups, correlated, uncorrelated, and anticorrelated, accordingly as its value is more than, equal to, or less than 0.5 , respectively. Again, this signifies the corresponding presence of attractive, zero, or repulsive forces in the system, with the 
deviation of the value of $H$ from 0.5 serving as a measure of the strength of the force. This has proved to be a very useful technique to gauge forces is soft and complex matter where a direct measurement is extremely difficult [31-33].

\subsection{Results}

Scanning Electron Microscopy and Hirsch Parameter: Figure 1 represents the FE-SEM images of some of the bare polymer surfaces (Figures $1(\mathrm{a})$ and $1(\mathrm{~b})$ ) and the surfaces of the same polymers immersed for 24 hrs in BSA(Figures $1(\mathrm{c})$ and $1(\mathrm{~d})$ ). The mean square density fluctuation (MSDF) $F(r)$, and the $H$-values from the $\log$-log plots of $F(r)$ versus $r$, extracted from these images are also presented in this figure (Figures $1(\mathrm{e})-1(\mathrm{~h})$ ). It is clear that the $H$-values have different constant values over three different length scales, around $100 \mathrm{~nm}, 500 \mathrm{~nm}$, and $2000 \mathrm{~nm}$ or $2 \mu \mathrm{m}$. It is interesting to note that the first length scale matches with the contour length of BSA, which will be attained by a BSA molecule fully stretched on the substrate surface, while the last matches with the dimensions of most bacteria. 


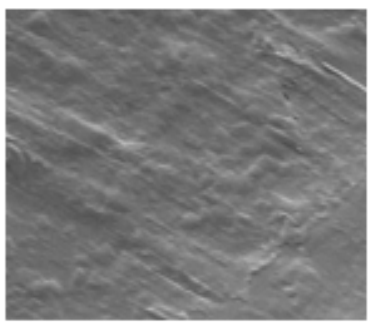

(a)

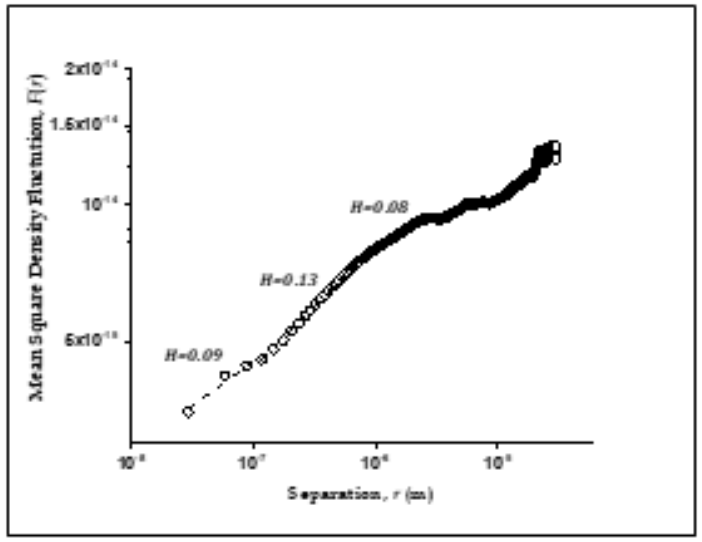

(e)

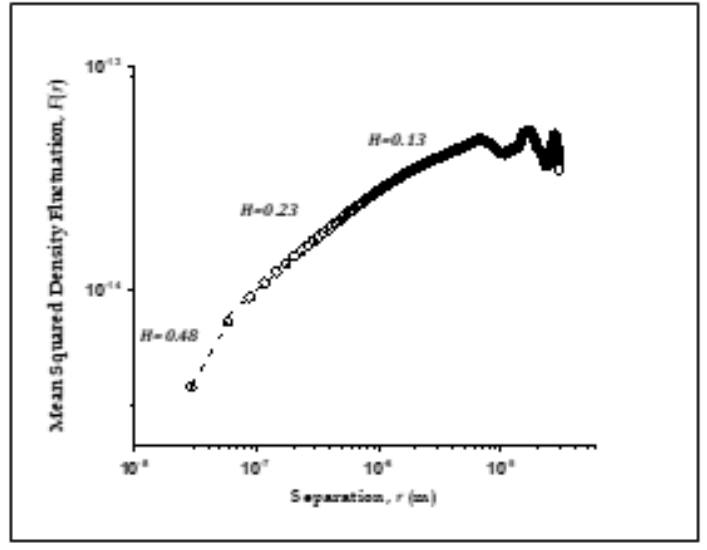

(g)

(b)
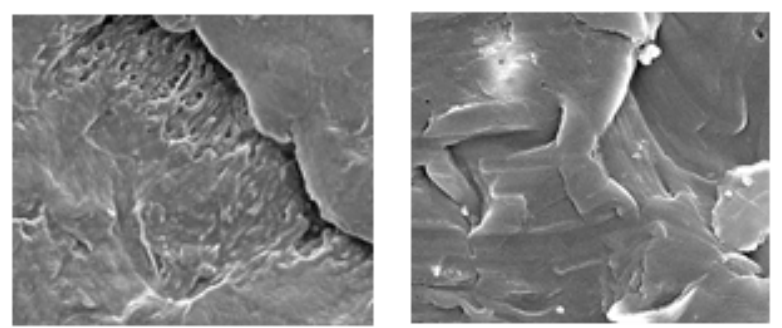

(c)

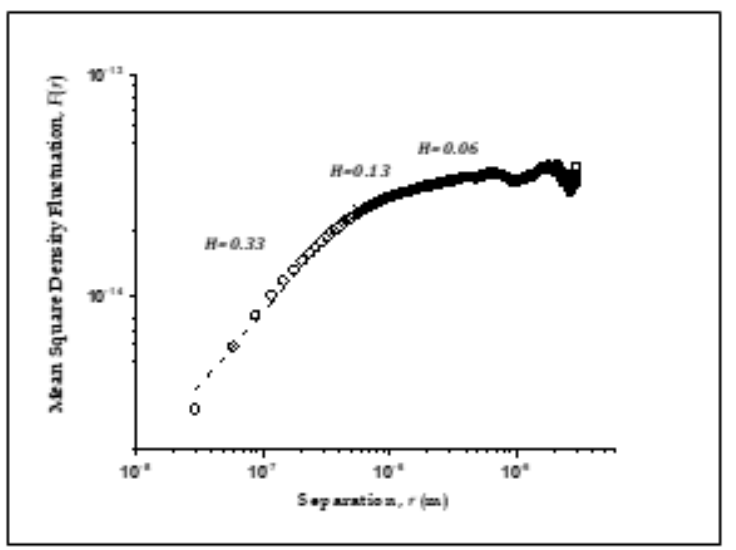

(f)

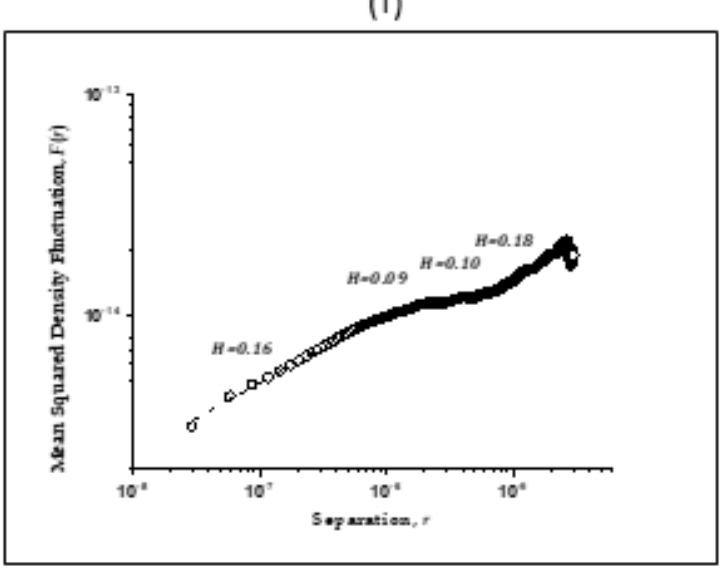

(h)

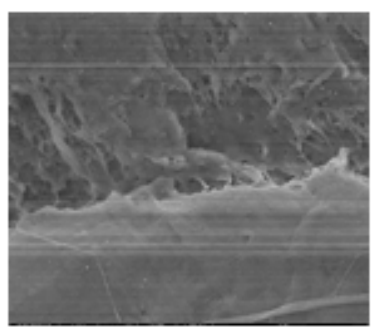

(d)

Figure 1: Representative Scanning Electron Microscopic (FE-SEM) images and mean squared density fluctuation (MSDF) of bare and Bovine Serum Albumin (BSA) coated polymers. (a)-(d): FESEM images, (e)-(h): MSDF, $F(r)$ versus $r$ (in $\mathrm{m}$ ) extracted from (a)-(d). Bare (a) High Density Polyethene (HDPE), (b) Polytetrafluoroethylene (PTFE) and 24 hrs BSA immersed (c) HDPE and (d) PTFE. (e) MSDF from (a), (f) MSDF from (b), (g) MSDF from (c), (h) MSDF from (d). Log-log plot of data are shown in open circles. Fits with $F(r) \sim r^{2 H}$ are shown in dashed lines, with values of the Hirsch parameter $H$ shown beside fitted segments.

Philicity and Hirsch Parameter: Figure 2 summarizes the results obtained from CAM measurements (SI) on bare HDPE, PTFE, PP, and PC, and on these polymers kept immersed in BSA for 9 hrs and for 24 hrs and compares these with those obtained from FE-SEM measurements of these polymers 
after 24 hrs of BSA immersion. It shows the values of 'philicity' from the CAM measurements and $H$-values from the FE-SEM measurements. The major common trend from 'philicity' values is a change from hydrophobicity for bare and for 9 hrs immersed polymers to near amphiphilicity, 0.05 $>\phi>-0.05$, for 24 hrs immersed polymers. For $H$-values, the trend is anti-correlation at all length scales and for all BSA immersed polymers, other than for HDPE at $100 \mathrm{~nm}$ length scale where there is no correlation $(H \sim 0.5)$. It is also seen that the anti-correlation increases with the length scale. This indicates the presence of short and long-range repulsive forces in the BSA covering the polymer surfaces, except for HDPE, where at the short-range the repulsive and attractive forces balance each other.

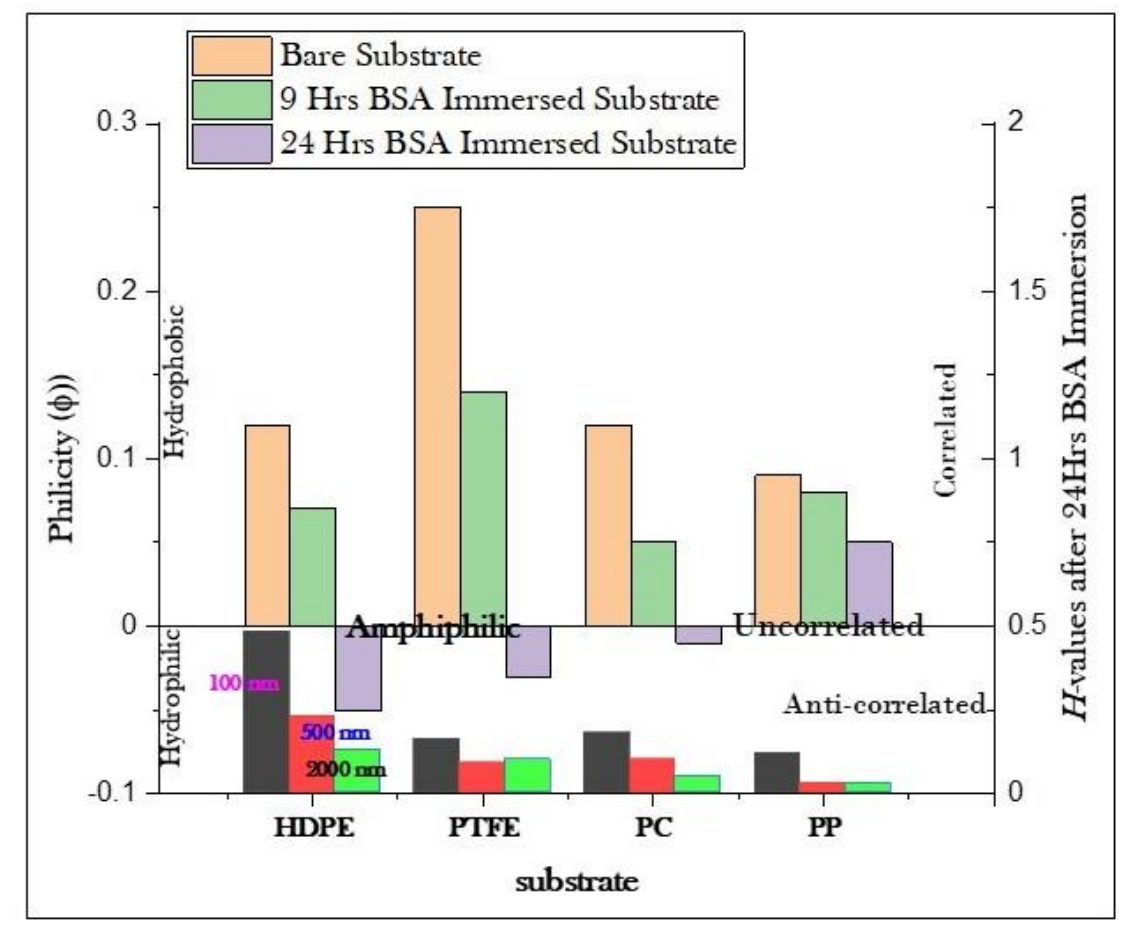

Figure 2: Philicity of the bare polymer substrates, substrates after 9 hrs and after 24 hrs of immersion in BSA, and Hirsch parameter values at different length scales for substrates after 24 hrs of immersion in BSA. Please see text for explanation of terms.

\subsection{Discussion}

A qualitative explanation of these results requires a look at some of the structural aspects of the polymers and BSA. The molecular structures are shown in Figure 3. The presence or absence of polar groups in the polymers and BSA is, of course, related to its hydrophilicity or hydrophobicity, respectively. In particular, a molecule with hydrocarbon or fluorocarbon chains and without any polar group will be strongly hydrophobic, whereas a molecule with a number of polar groups and much more so with dissociable groups will be strongly hydrophilic. When the proportions of the hydrocarbon part and the polar/dissociable part become equal or comparable, the molecule becomes amphiphilic. If a surface is dominated by hydrophobic or hydrophilic molecules it acquires the respective character. If there are either amphiphilic molecules or equal or comparable 
proportions of hydrophobic and hydrophilic molecules at the surface, the surface becomes amphiphilic.

Figures 3(a)-(d) show that the polymers have hydrocarbon/fluorocarbon moieties only or dominantly. On the other hand, BSA has a hydrocarbon backbone with disulphides, and a large number of amino acids (Figures $3(\mathrm{e})-(\mathrm{g}))$ polar and dissociable groups such as carboxyl $\left(\mathrm{CO}_{2}{ }^{-} \mathrm{H}^{+}\right)$, phosphatidyl $\left(\mathrm{PO}_{3}{ }^{2-} \mathrm{H}_{2}{ }^{2+}\right)$, and amine $\left(\mathrm{NH}_{2}\right)$ attached. The former explains the hydrophobicity of the bare polymers but the acquired near-amphiphilicity of the 24 hrs BSA immersed substrates calls for more explanation. The most plausible would be the presence of a short-range lipophilic interaction [20] between the hydrocarbon backbone of the BSA molecule and the polymer, which leaves the molecule stretched on the surface with polar/dissociable groups free. This later renders hydrophilicity to the already hydrophobic substrate surfaces and the balance makes the surfaces nearly amphiphilic.

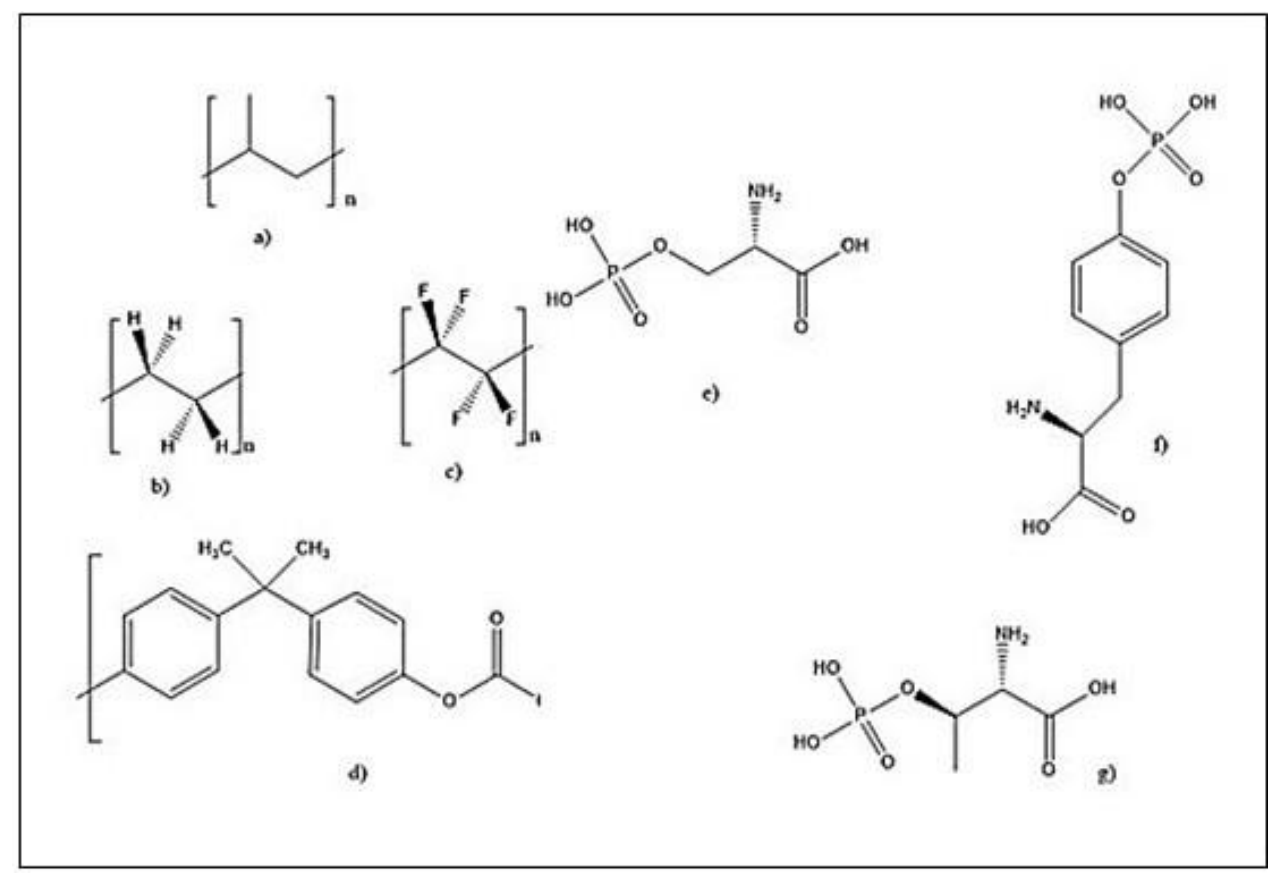

Figure 3: Structures of (a) Polyethene, (b) Polytetrafluoroethylene, (c) Polypropylene,

(d)Polycarbonate; Structures of (e) Phosphoserine, (f) Phosphotyrosine, and (g) Phosphothreonine.

The trend in intermolecular forces is consistent with this explanation since the repulsive force becomes stronger at longer ranges. At shorter ranges the lipophilic attraction between the hydrocarbon backbone of BSA and the polymer competes with the repulsion between the dipolar groups of BSA fixed on the substrate surfaces. At longer ranges, only the dipole-dipole repulsion remains [32]. 


\section{Part II: Bacterial Biofilms on BSA-coated Polymer Substrates}

\subsection{Materials and Methods}

\subsubsection{Bacterial Species}

The clinical strains of Gram-negative bacteria, E. coli and K. pneumoniae, were obtained isolated from fatally ill patients, through the central catheter system, of The Calcutta Medical Research Institute, Kolkata. The Gram-negative strains of E coli ATCC 25922 and Klebsiella pneumoniae ATCC 700603 were from American Type Culture Collection.

\subsubsection{Cell culture and preparation}

The bacteria were cultivated at $150 \mathrm{rpm}$ in standard Luria-Bertani (LB) medium (10 g of tryptone, 5 $\mathrm{g}$ of yeast extract, and $10 \mathrm{~g}$ of $\mathrm{NaCl}$ per $1 \mathrm{~L}$ of deionized water, $\mathrm{pH}$ adjusted to 7.2 and sterilized at $121{ }^{\circ} \mathrm{C}$ for $20 \mathrm{~min}$ ). The cultivation temperature for $E$. coli and $K$. pneumoniae was $37^{\circ} \mathrm{C}$. Cells were harvested in the stationary phase after 24 hrs cultivation. The bacteria cells were collected by centrifugation (3,000 rpm, $4^{\circ} \mathrm{C}, 10 \mathrm{~min}$ ) and washed three times in $165 \mathrm{mM}$ phosphate buffer saline (PBS, composition 1.093 $\mathrm{g} \mathrm{Na}_{2} \mathrm{HPO}_{4}, 0.276 \mathrm{~g} \mathrm{NaH} 2 \mathrm{PO}_{4}$, and $8.475 \mathrm{~g} \mathrm{NaCl}$ in $1 \mathrm{~L}$ deionized water, $\mathrm{pH}$ adjusted to 7.2 and sterilized at $121^{\circ} \mathrm{C}$ for $20 \mathrm{~min}$ ) to remove the residual LB medium. Bacterial cells were resuspended in PBS to a concentration equivalent to an optical density at $600 \mathrm{~nm}$ (OD $600 \mathrm{~nm}$ ) of about 0.2. The suspension was then used for cell adhesion and biofilm cultivation immediately.

\subsubsection{Growth of biofilms}

The protocol for biofilm growth [28] was followed with the four sets of polymer chips with BSA adsorbed on them for 24 hours, and three samples of each type were placed in separate wells of a 24 well tissue culture plate with identical growth conditions. Biofilm were simultaneously grown on three samples of each type of bare polymer (without BSA) - following the same protocol. After the completion of the 7-day growth period, the polymer chips were aseptically removed and washed thrice with phosphate buffered saline (PBS pH 7.2) to remove planktonic bacteria. The chips were then air dried and prepared for Field Emission-Scanning Electron Microscopy (FE-SEM) measurements.

\subsubsection{Field Emission-Scanning Electron Microscopy (FE-SEM)}

The polymer chips with attached bacterial cells (with or without a conditioning layer of BSA), were covered with $2.5 \%$ glutaraldehyde and kept for 3 hrs in $4{ }^{\circ} \mathrm{C}$ after which they were washed thrice with the phosphate buffer solution. They were then passed once through the graded series of alcohol (25, 50 and 75\%, twice through $100 \%$ ethanol) each for $10 \mathrm{~min}$, finally transferred to the critical point drier and kept overnight to make them ready for biofilm analysis. The dried polymer chips with biofilms were sputter-coated with a 3-nm-thick conductive layer of gold. To compare the 7-day old biofilms produced by the clinically isolated and ATCC strains of E. coli and $K$. pneumoniae, on different substrates, FE-SEM measurements were conducted at $2.0-10 \mathrm{kV}$ with a 
Inspect F50 Microscope (FEI Europe BV, and The Netherlands; FP 2031/12, SE Detector R580). We have used Image J again for analysis of the FE-SEM images.

\subsubsection{Fourier Transform Infrared (FTIR) Spectroscopy}

All FTIR spectra were obtained using a Fourier Transform Infrared Spectrometer from Shidzu, having temperature-stabilized DTGS (Deuterated Triglycine Sulfate) detectors optimized for MIR with an enhanced SNR of 15,00o:1 peak-to-peak for a 5 second scan. The system had KBr beam splitter for MIR for a spectral range $8,300-350 \mathrm{~cm}^{-1}$ at a best resolution of $0.4 \mathrm{~cm}^{-1}$. The samples were tightly fastened to the sample holder before the measurements and it was confirmed that there was absolutely no space between the two. The spectra of polymer samples with and without BSA, with biofilms attached on them were obtained after running the background scan. The final spectrum in each case was obtained after the background correction.

\subsubsection{Surface Enhanced Raman Spectroscopy (SERS)}

AgNPs were prepared [34] by reduction of silver nitrate with hydroxylamine hydrochloride at alkaline $\mathrm{pH}$ and room temperature [35]. Briefly, $10 \mathrm{~mL}$ of silver nitrate $\left(10^{-2} \mathrm{M}\right)$ was rapidly added, while stirring, into $90 \mathrm{~mL}$ of premixed solution containing hydroxylamine hydrochloride $\left(1.67 \times 10^{-3}\right.$ $\mathrm{M})$ and sodium hydroxide $\left(3.33 \times 10^{-3} \mathrm{M}\right)$. Then, the solution was being stirred for 1 min to enable the overall reaction to complete. The AgNP solution was stored in darkness at $4{ }^{\circ} \mathrm{C}$. The SERS experiments were done with freshly prepared AgNP solution.

All SERS data were obtained using Lab Ram HR 800 (Horiba Jobin Yvon) spectrometer. The instrument acquired data over a range of $100 \mathrm{~cm}^{-1}$ to $3000 \mathrm{~cm}^{-1}$ with a $5 \mathrm{~s}$ exposure time. The laser power was $17 \mathrm{~mW}$, and the operating wavelength of the laser was $632.8 \mathrm{~nm}$. Spectral detection was done using a CCD detector. An Olympus optical microscope was attached to the system and observations were repeated with x10 and x100 objectives, to check for accuracy. All measurements were carried out under identical conditions to enable comparative analysis. $200 \mu \mathrm{L}$ of prepared AgNP solution was added on the polymer chips with biofilms attached on them, prior to the measurements [36,37]. The samples were then stored in darkness and dried at room temperature. The laser beam was focused on the bacterial layer by applying the Leica $\times 100$ (NA o.85) objective to a spot of approximately $1 \mu \mathrm{m}$ diameter.

\subsection{Results}

Scanning Electron Microscopy and Hirsch Parameter: Figures 4(a)-(d) present the FE-SEM images of some representative bacterial biofilms grown on substrates that had been immersed in BSA for 24 hrs. While Figures 4(a) and 4(b) show the images of American Type Culture Collection or ATCC strain of $K$. pneumoniae grown on BSA-coated HDPE and PTFE, respectively, Figures 4(c) and 4(d) show images of ATCC strain of E. coli grown on corresponding substrates. Figures $4(\mathrm{e})-(\mathrm{h})$ show the MSDF (log-log plots of $F(r)$ versus $r$ ) extracted from Figures 4(a)-(d), respectively, with the $H$ values for the $100 \mathrm{~nm}, 500 \mathrm{~nm}$, and $2 \mu \mathrm{m}$ length scales extracted from these plots. From the FE-SEM 
images, the high coverage of the surfaces by the biofilms is apparent, pointing to the good growth of the latter.

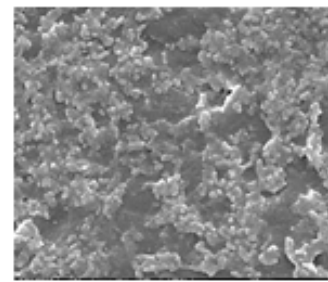

(a)

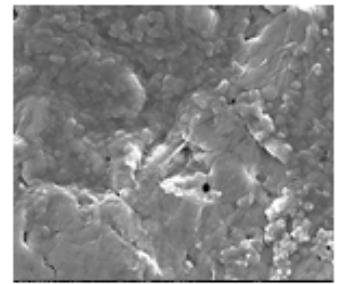

(b)

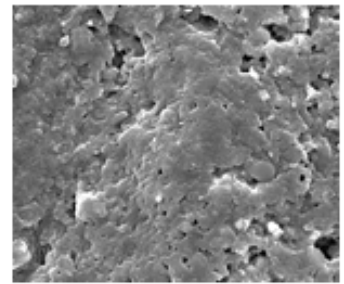

(c)

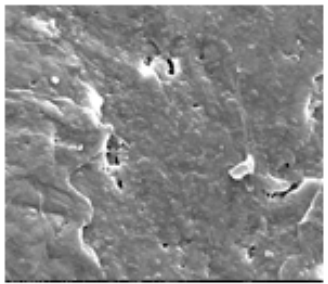

(d)

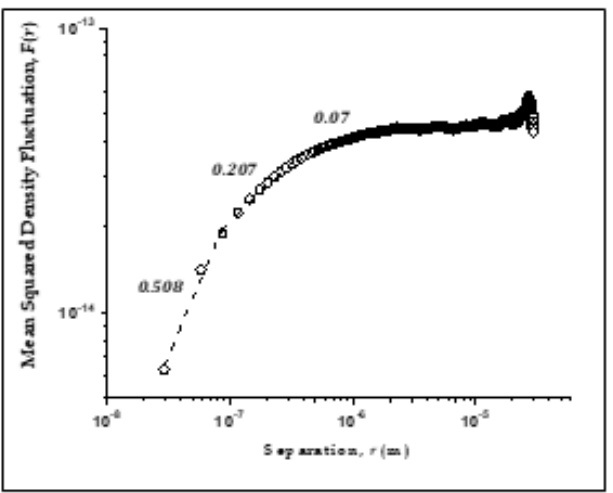

(e)

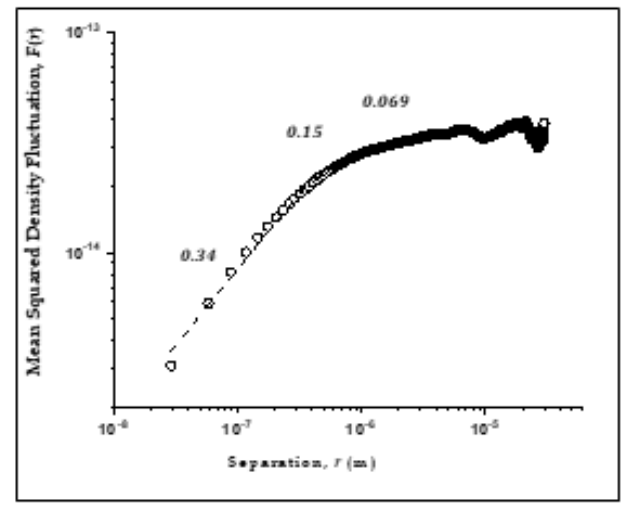

(g)

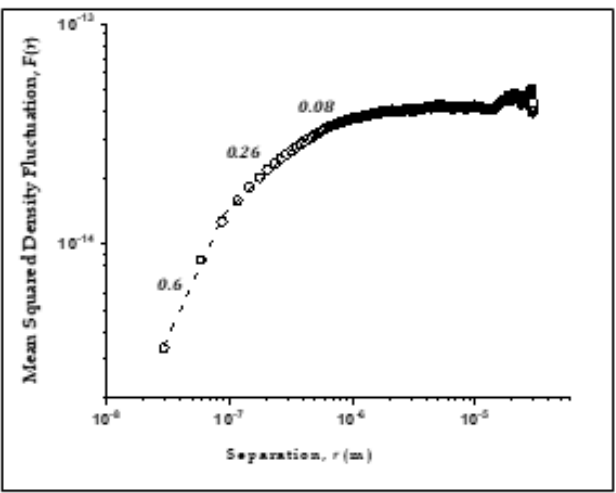

(f)

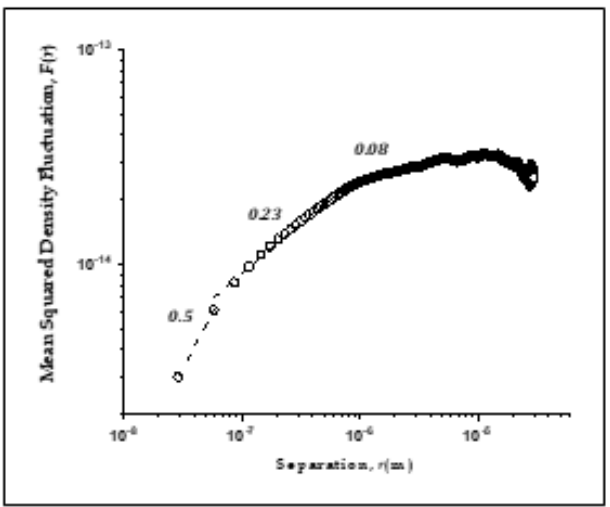

(h)

Figure 4: Representative FE-SEM images and MSDF of biofilms grown on BSA (24 hrs) coated polymers. (a)-(d): FE-SEM images, (e)-(h): MSDF, $F(r)$ versus $r$ (in m) extracted from (a)-(d). Klebsiella pneumoniae (American Type Culture Collection or ATCC) on BSA-coated (a)HDPE, (b) PTFE and Escherichia coli (ATCC) on BSA-coated (c) HDPE, (d) PTFE. (e) MSDF from (a), (f) MSDF from (b), (g) MSDF from (c), (h) MSDF from (d). Log-log plot of data are shown in open circles. Fits with $F(r) \sim r^{2 H}$ are shown in dashed lines, with values of the Hirsch parameter $H$ shown beside fitted segments. 


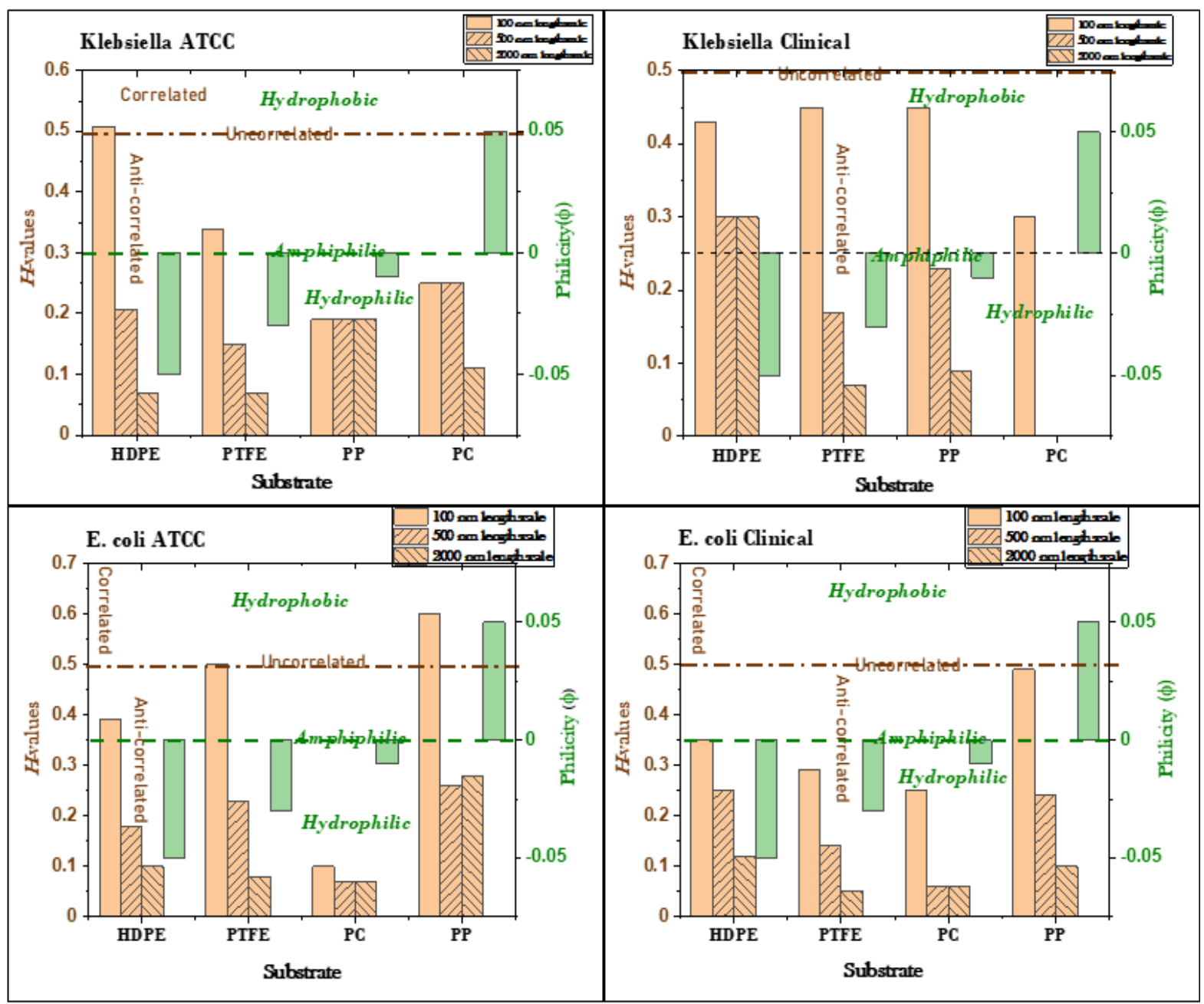

Figure 5: Philicity and Hirsch parameter values at different length scales of the polymer substrates coated with BSA (24 hrs of immersion) and bacterial biofilms on BSA. Top: Klebsiella pneumoniae ATCC and Clinical bacterial biofilms; Bottom: Escherichia coli ATCC and Clinical bacterial biofilms.

Philicity and Hirsch Parameter: Figure 5 summarizes the results obtained from CAM and FE-SEM measurements on biofilms of ATCC and Clinical strains of $K$. pneumoniae (top) and E. coli (bottom) grown on the polymers after $24 \mathrm{hr}$ immersion in BSA. From philicity values, the most interesting feature is that these values are independent of the bacterial species and strain but totally dependent on the polymer as the substrate, or in other words, the BSA-polymer interaction has already decided the wetting properties of the biofilms. The next most important feature is the near absence of any change in the 'philicities' of the biofilms from those of the BSA-coated polymers shown in Figure 2, which is again consistent with the above proposition.

The intermolecular forces on the other hand, as suggested by the $H$-values in Figure 5, show some variation from bacteria to bacteria and also between different strains of the same bacteria. However, the same general trend of short-range attraction competing with repulsion and the stronger repulsion at long range are very much present, consistent with lipophilic and dipolar forces. 


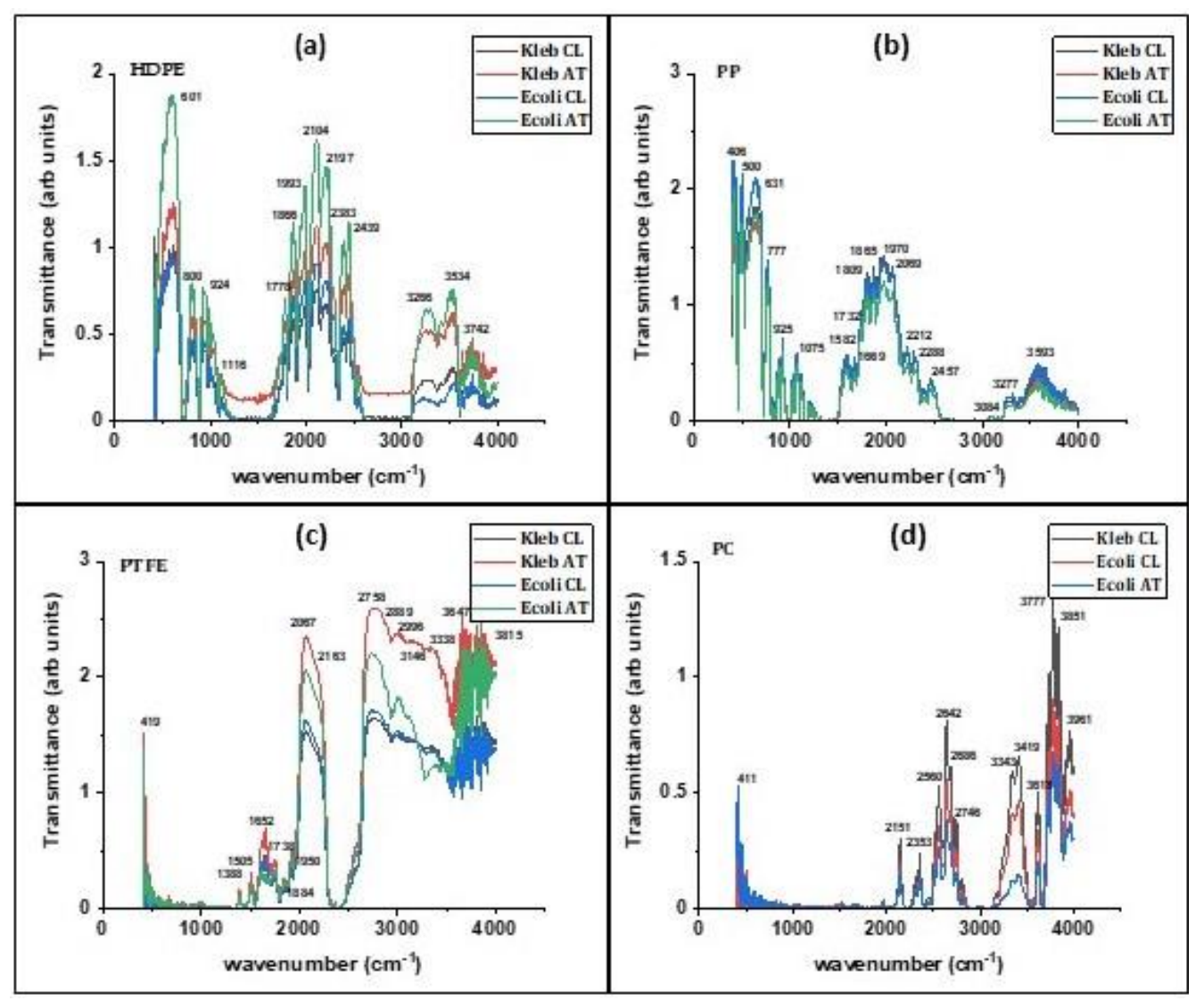

Figure 6: Fourier Transform Infrared Spectra of the bacterial biofilms. Klebsiella pneumoniae ATCC and Clinical, and Escherichia coli ATCC and Clinical bacterial biofilms grown on (a) HDPE, (b) PP, (c) PTFE, and (d) PC. Prominent peak positions are given in $\mathrm{cm}^{-1}$.

Table 1

Fourier Transform Infrared Spectra of K. pneumoniae ATCC, K. pneumoniae Clinical, E. coli ATCC and $E$. coli Clinical bacterial biofilms grown on BSA-coated

(a) HDPE

\begin{tabular}{lll}
\hline Peak position $\left(\mathbf{c m}^{-1}\right)$ & Tentative assignment & Probable source \\
\hline $\mathbf{6 0 1}$ & Out-of-plane C=O bend & Protein \\
$\mathbf{8 0 0}$ & Out-of-plane NH bend & Protein \\
$\mathbf{9 2 4}$ & C-O-C bridge & Polysaccharide \\
$\mathbf{1 1 1 8}$ & Glycosidic C-O stretch & Polysaccharide \\
$\mathbf{1 7 7 8}$ & C=O stretch & Lipid, Protein \\
$\mathbf{1 8 6 8}$ & C=O stretch & Lipid, Protein \\
1993 & Aromatic CH bend & Protein \\
\hline
\end{tabular}




\begin{tabular}{llll}
\hline $\mathbf{2 1 0 4}$ & $\mathrm{S}-\mathrm{C} \equiv \mathrm{N}$ mode $($ wag?) & $\begin{array}{l}\text { Protein-disulphide } \\
(?)\end{array}$ & bonding \\
$\mathbf{2 1 9 7}$ & $\mathrm{S}-\mathrm{C} \equiv \mathrm{N}$ mode $($ symm stretch?) & $\begin{array}{l}\text { Protein-disulphide } \\
(?)\end{array}$ & bonding \\
$\mathbf{2 3 8 3}$ & $\mathrm{S}-\mathrm{C} \equiv \mathrm{N}$ mode $($ asymm stretch?) & $\begin{array}{l}\text { Protein-disulphide } \\
(?)\end{array}$ & bonding \\
$\mathbf{2 4 3 9}$ & $\mathrm{CH}$ stretch & $\begin{array}{l}\text { Polysaccharide } \\
\mathbf{3 2 6 8}\end{array}$ & Protein \\
$\mathbf{3 6 3 4}$ & OH stretch & Polysaccharide \\
$\mathbf{3 7 4 2}$ & OH stretch & Polysaccharide & \\
\hline
\end{tabular}

(b) PP

\begin{tabular}{|c|c|c|}
\hline Peak position $\left(\mathrm{cm}^{-1}\right)$ & Tentative assignment & Probable source \\
\hline 600 & Out-of-plane $\mathrm{C}=\mathrm{O}$ bend & Protein \\
\hline 777 & Out-of-plane NH bend & Protein \\
\hline 926 & $\mathrm{C}-\mathrm{O}-\mathrm{C}$ bridge & Polysaccharide \\
\hline 1076 & Glycosidic C-O stretch & Polysaccharide \\
\hline 1682 & $\mathrm{C}=\mathrm{O}$ stretch & Polysaccharide \\
\hline 1732 & $\mathrm{C}=\mathrm{O}$ stretch & Lipid, Protein \\
\hline 1809 & $\mathrm{C}=\mathrm{O}$ stretch & Lipid, Protein \\
\hline 1886 & Aromatic $\mathrm{CH}$ bend & Protein \\
\hline 1970 & Aromatic $\mathrm{CH}$ bend & Protein \\
\hline 2069 & $\mathrm{~S}-\mathrm{C} \equiv \mathrm{N}$ mode (wag?) & $\begin{array}{l}\text { Protein-disulphide bonding } \\
\text { (?) }\end{array}$ \\
\hline 2212 & $\mathrm{~S}-\mathrm{C} \equiv \mathrm{N}$ mode (symm stretch?) & $\begin{array}{l}\text { Protein-disulphide bonding } \\
\text { (?) }\end{array}$ \\
\hline 2288 & $\mathrm{~S}-\mathrm{C} \equiv \mathrm{N}$ mode (asymm stretch?) & $\begin{array}{l}\text { Protein-disulphide bonding } \\
\text { (?) }\end{array}$ \\
\hline 2467 & $\mathrm{CH}$ stretch & Polysaccharide \\
\hline 3084 & NH stretch & Protein \\
\hline 3277 & OH stretch & Polysaccharide \\
\hline 3693 & OH stretch & Polysaccharide \\
\hline
\end{tabular}

(c) PTFE

\begin{tabular}{llll}
\hline Peak position $\left(\mathbf{c m}^{-1}\right)$ & Tentative assignment & Probable source & \\
\hline $\mathbf{1 3 8 8}$ & OH bend (carboxylic acid) & Protein & \\
$\mathbf{1 6 0 6}$ & NH bend (primary amine) & Protein & \\
$\mathbf{1 6 6 2}$ & $\mathrm{C}=\mathrm{O}$ stretch $(\delta$-lactam $\mathrm{COOH})$ & Protein \\
$\mathbf{1 7 3 8}$ & $\mathrm{C}=\mathrm{O}$ stretch $(\delta$-lactone) & Protein \\
$\mathbf{1 8 8 4}$ & Aromatic $\mathrm{CH}$ bend & Protein & \\
$\mathbf{1 9 6 0}$ & Aromatic $\mathrm{CH}$ bend & Protein & \\
$\mathbf{2 0 6 7}$ & $\mathrm{N}=\mathrm{C}=\mathrm{S}$ stretch & $\begin{array}{l}\text { Protein-disulphide } \\
(?)\end{array}$ & bonding \\
& & Protein-disulphide & bonding \\
$\mathbf{2 1 6 3}$ & $\mathrm{S}-\mathrm{C} \equiv \mathrm{N}$ stretch & & \\
& & & \\
\hline
\end{tabular}




\begin{tabular}{lll}
\hline $\mathbf{2 7 5 8}$ & CH stretch (aldehyde) & Polysaccharide \\
$\mathbf{2 8 8 9}$ & CH stretch (alkane) & Hydrocarbon chain \\
$\mathbf{2 9 9 6}$ & CH stretch (alkane) & Hydrocarbon chain \\
$\mathbf{3 1 4 6}$ & OH stretch (carboxylic acid) & Protein \\
$\mathbf{3 3 3 8}$ & NH stretch (secondary amine) & Protein \\
$\mathbf{3 6 4 7}$ & OH stretch (intermolecular & Polysaccharide \\
& bonded alcohol) & \\
$\mathbf{3 8 1 5}$ & $\begin{array}{l}\text { OH stretch (intermolecular } \\
\text { bonded alcohol) }\end{array}$ & Polysaccharide \\
\hline
\end{tabular}

(d) PC

\begin{tabular}{|c|c|c|}
\hline Peak position $\left(\mathrm{cm}^{-1}\right)$ & Tentative assignment & Probable source \\
\hline 2151 & $\mathrm{~S}-\mathrm{C} \equiv \mathrm{N}$ stretch & $\begin{array}{l}\text { Protein-disulphide bonding } \\
\text { (?) }\end{array}$ \\
\hline 2353 & $\mathrm{~N}=\mathrm{C}=\mathrm{O}$ stretch & Protein (oxidised?) \\
\hline 2560 & SH stretch & Protein \\
\hline 2642 & CH stretch (aldehyde) & Polysaccharide \\
\hline 2686 & CH stretch (aldehyde) & Polysaccharide \\
\hline 2746 & CH stretch (aldehyde) & Polysaccharide \\
\hline 3343 & NH stretch (secondary amine) & Protein \\
\hline 3419 & NH stretch (primary amine) & Protein \\
\hline 3618 & $\begin{array}{l}\mathrm{OH} \text { stretch (intermolecular } \\
\text { bonded alcohol) }\end{array}$ & Polysaccharide \\
\hline 3777 & $\begin{array}{l}\mathrm{OH} \text { stretch (intermolecular } \\
\text { bonded alcohol) }\end{array}$ & Polysaccharide \\
\hline 3851 & $\begin{array}{l}\mathrm{OH} \text { stretch (intermolecular } \\
\text { bonded alcohol) }\end{array}$ & Polysaccharide \\
\hline
\end{tabular}




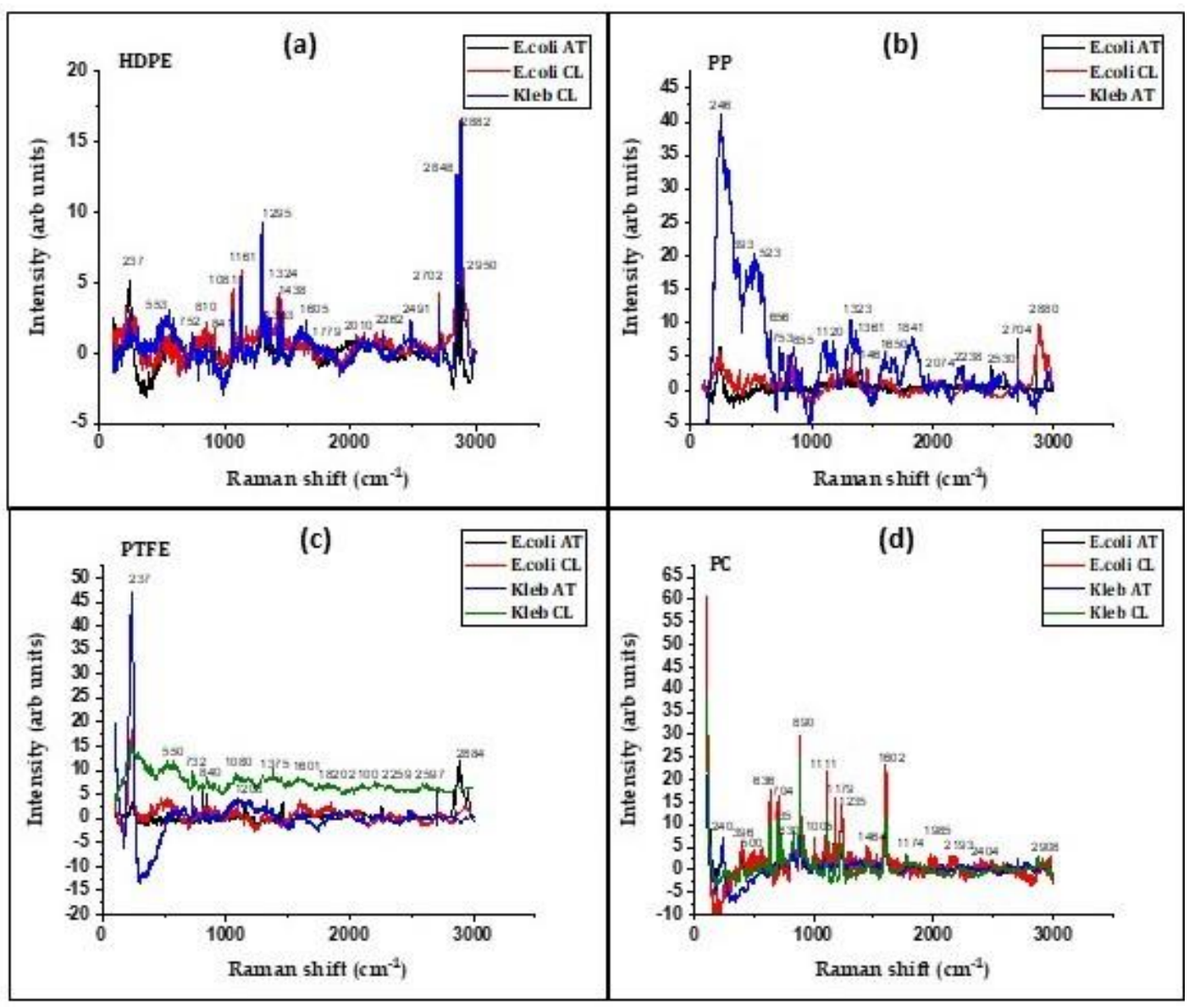

Figure 7: Surface Enhanced Raman Spectra of the bacterial biofilms. Klebsiella pneumoniae ATCC and Clinical, and Escherichia coli ATCC and Clinical bacterial biofilms grown on (a) HDPE, (b) PP, (c) PTFE, and (d) PC. Prominent peak positions are given in $\mathrm{cm}^{-1}$.

Table 2

Surface Enhanced Raman Spectra of K. pneumoniae ATCC, K. pneumoniae Clinical, E. coli ATCC and E. coli Clinical bacterial biofilms grown on BSA-coated

(a) HDPE

\begin{tabular}{lll}
\hline Peak position $\left(\mathbf{c m}^{-1}\right)$ & Tentative assignment & Probable source \\
\hline $\mathbf{5 5 3}$ & S-S stretch & Polysaccharide \\
$\mathbf{7 5 2}$ & Adenine ring deformation & Nucleic Acid \\
$\mathbf{8 1 0}$ & O-P-O stretch & Lipid \\
$\mathbf{8 4 1}$ & Tyrosine Fermi resonance & Protein \\
$\mathbf{1 0 8 1}$ & C-O-C Glycosidic breathing & Polysaccharide \\
$\mathbf{1 1 6 1}$ & Tyrosine C-N stretch & Protein \\
$\mathbf{1 2 9 5}$ & C-O-H/H-C-C deformation & Polysaccharide \\
$\mathbf{1 3 2 4}$ & C-H deformation & Protein \\
$\mathbf{1 3 5 3}$ & C=C stretch & Lipid \\
\hline
\end{tabular}




\begin{tabular}{lll}
\hline $\mathbf{1 4 3 8}$ & $\mathrm{C}-\mathrm{H}_{2} / \mathrm{CH}_{3}$ deformation & Lipid \\
$\mathbf{1 6 0 5}$ & $\mathrm{C}-\mathrm{COOH}$ stretch & Protein \\
\hline
\end{tabular}

(b) PP

\begin{tabular}{lll}
\hline Peak position $\left(\mathbf{c m}^{-1}\right)$ & Tentative assignment & Probable source \\
\hline 393 & & Polysaccharide \\
$\mathbf{5 2 3}$ & S-S stretch & Polysaccharide \\
$\mathbf{6 5 6}$ & Tyrosine C-S stretch & Protein \\
$\mathbf{7 5 3}$ & Adenine ring deformation & Nucleic Acid \\
$\mathbf{8 5 5}$ & Tyrosine Fermi resonance & Protein \\
$\mathbf{1 1 2 0}$ & C-O-C Glycosidic breathing & Polysaccharide \\
$\mathbf{1 3 2 3}$ & C-H deformation & Protein \\
$\mathbf{1 3 6 1}$ & $\mathrm{C}=\mathrm{C}$ stretch & Lipid \\
$\mathbf{1 4 6 1}$ & $\mathrm{C}-\mathrm{H}_{2} / \mathrm{CH}_{3}$ deformation & Lipid \\
$\mathbf{1 6 5 0}$ & Amide & Protein \\
\hline (c) PTFE & & \\
& & \\
\hline Peak position $\left(\mathbf{c m}^{-1}\right)$ & Tentative assignment & Probable source \\
\hline $\mathbf{5 5 0}$ & S-S stretch & Polysaccharide \\
$\mathbf{7 3 2}$ & Adenine & Nucleic Acid \\
$\mathbf{8 4 0}$ & Tyrosine Fermi resonance & Protein \\
$\mathbf{1 0 8 0}$ & C-O-C Glycosidic breathing & Polysaccharide \\
$\mathbf{1 2 0 3}$ & Phenylalanine & Protein \\
\hline $\mathbf{1 3 7 5}$ & C=C stretch & Lipid \\
$\mathbf{1 6 0 1}$ & C-COOH & Protein \\
\hline
\end{tabular}

(d) PC

\begin{tabular}{lll}
\hline Peak position $\left(\mathbf{c m}^{-1}\right)$ & Tentative assignment & Probable source \\
\hline $\mathbf{3 9 6}$ & & Polysaccharide \\
$\mathbf{5 0 0}$ & S-S stretch & Polysaccharide \\
$\mathbf{6 3 6}$ & Tyrosine C-S stretch & Protein \\
$\mathbf{7 0 4}$ & & Protein \\
$\mathbf{7 3 5}$ & Adenine ring deformation & Nucleic Acid \\
$\mathbf{8 3 0}$ & Tyrosine Fermi resonance & Protein \\
$\mathbf{8 9 0}$ & & Protein \\
$\mathbf{1 0 0 5}$ & Tryptophan ring breathing & Protein \\
$\mathbf{1 1 1 1}$ & Tyrosine $\mathrm{C}-\mathrm{N}$ stretch & Protein \\
$\mathbf{1 1 7 9}$ & $\mathrm{C}-\mathrm{C}$ stretch & Carotenoid \\
$\mathbf{1 2 3 5}$ & Amide III & Protein \\
\hline $\mathbf{1 4 3 8}$ & $\mathrm{C}-\mathrm{H}_{2} / \mathrm{CH}_{3}$ deformation & Lipid \\
$\mathbf{1 6 0 5}$ & $\mathrm{C}-\mathrm{COOH}$ stretch & Protein \\
\hline
\end{tabular}


FTIR and SERS: These expectations are completely borne out by the results of FTIR spectroscopy and of SERS on the biofilms shown in Figure 6 and Figure 7, respectively. The tentative assignment of some of the major peaks in these figures and the probable source of these assigned groups are given, respectively, in Table 1 and Table 2. Both types of spectra again show, strikingly, that the spectra are almost identical for the different species and strains of bacteria on the same polymeric substrate, while they are completely different for the same species and strain of bacteria on different polymers. This establishes the fact that the composition of EPS generated by the biofilm on a specific BSA-coated polymeric substrate is decided by the specific BSA-polymer interaction.

\subsection{Discussion}

The above observations suggest that the EPS of the biofilm, secreted by the bacteria is generated to interact with the hydrocarbon and dipolar/dissociable moieties of the BSA-covered substrates to reduce the surface free energy for stable growth of the biofilm. As discussed in section 2.3, the distribution of these moieties on a BSA-covered polymer surface is decided by the specific polymerBSA interaction. Thus, it is expected that the EPS of a biofilm on a particular BSA-covered polymer surface will also be largely decided by the polymer-BSA interaction of that surface. It is also interesting to note that the EPS on BSA-HDPE and on BSA-PP are almost identical and polysaccharide-rich, - consistent with the homologous composition of these polymers. The EPS on BSA-PTFE is protein-rich whereas that on BSA-PC has close proportions of polysaccharides and proteins.

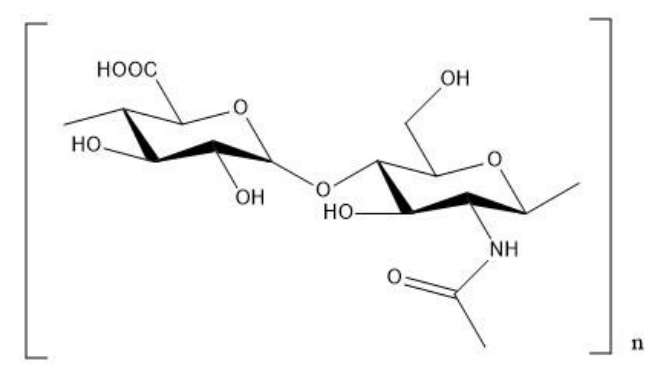

Figure 8. Molecular structure of a generic polysaccharide.

Inspection of the generic structure of polysaccharides (Figure 8) richer in hydroxyl groups than proteins (richer in the carboxyl and amine groups) may give some idea as to the specific interactions involved in producing the EPS. In absence of spatially resolved spectroscopic data a clearer picture is not available at this stage and work towards that end is underway.

\section{Conclusion and Outlook}

We have carried out Contact Angle Measurements, Scanning Electron Microscopy, Fourier Transform Infrared Spectroscopy, and Surface Enhanced Raman Spectroscopy of biofilms of $K$. pneumoniae and E. coli (ATCC and Clinical strains) on polymer substrates - HDPE, PTFE, PP, and PC which had been previously adsorbed with BSA for 24 hours. These studies prove conclusively that the BSA-polymer interaction decides the wetting properties, the intermolecular forces and the composition of the EPS of the bacterial biofilms, irrespective of the strain and type of bacteria involved. 
These results are to be extended to gram positive bacteria and in vivo studies for understanding the specific nature of the BSA-polymer interaction and its role in the growth of the EPS. They form the first step towards the final goals of elimination of clinically pathogenic biofilms from physiological environments through noninvasive methods. Such studies will also have the potential for developing suitable biomaterial surfaces for negation of biofilm formation and may be extended for the enhancement of beneficial biofilms for widespread applications in environmental protection.

Acknowledgements: The research has been carried out with the support of The Royal Society Grant (NIF $\backslash$ Ri $\backslash 181300)$. S DuttaSinha is thankful to The Royal Society, UK and Science and Engineering research Board (SERB), India for granting a Newton International Fellowship. AD would like to thank the Department of Atomic Energy, Government of India for a Raja Ramanna Fellowship, the Director, CSIR-Central Glass and Ceramic Research Institute for hosting the position of Emeritus Scientist, and Swapnasopan Datta of Jawaharlal Nehru Centre for Advanced Scientific Research for the figures of the molecular structures

\section{Data availability statement:}

The raw/processed data required to reproduce these findings cannot be shared at this time as the data also forms part of an ongoing study.

\section{References:}

[1] Serra, Diego O., and Regine Hengge. "Stress responses go three dimensional-the spatial order of physiological differentiation in bacterial macrocolony biofilms." Environmental microbiology 16, no. 6 (2014): 1455-1471. doi:10.1111/1462-2920.12483

[2] Pompilio, Arianna, Raffaele Piccolomini, Carla Picciani, Domenico D'Antonio, Vincenzo Savini, and Giovanni Di Bonaventura. "Factors associated with adherence to and biofilm formation on polystyrene by Stenotrophomonas maltophilia: the role of cell surface hydrophobicity and motility." FEMS microbiology letters 287, no. 1 (2008): 41-47. doi.org/10.1111/j.1574-6968. 2008. 01292.X

[3] Ma, Luyan, Kara D. Jackson, Rebecca M. Landry, Matthew R. Parsek, and Daniel J. Wozniak. "Analysis of Pseudomonas aeruginosa conditional psl variants reveals roles for the psl polysaccharide in adhesion and maintaining biofilm structure post attachment." Journal of bacteriology 188, no. 23 (2006): 8213-8221. doi:10.1128/JB.01202-06

[4] Sherr EB, Sherr BF. (2008). Understanding roles of microbes in marine pelagic food webs: a brief history in microbial ecology of the oceans, Kirchman DL (ed.) Wiley-Liss: New York. pp, 27-44. DOI:10.1002/9780470281840. 
[5]. Ducklow HW. (200o). Bacterial production and biomass in the oceans in microbial ecology of the oceans.Kirchman DL (ed.). Wiley-Liss: New York. pp, 85-120. DOI:10.1002/9780470281840

[6]. Caron DA. (2009). New accomplishments and approaches for assessing protistan diversity and ecology in natural ecosystems. Bioscience 59: 287-299. doi.org/10.1525/bio.2009.59.4.7

[7]. Flemming HC, Wuertz S. Bacteria and archaea on Earth and their abundance in biofilms. Nature Reviews Microbiology. 2019 Apr;17(4):247-6o. doi.org/10.1038/s41579-019-0158-9

[8]. Ghannoum M, Parsek M, Whiteley M, Mukherjee PK, editors. Microbial biofilms. John Wiley \& Sons; 2020 Aug 11. doi:10.1128/9781555817466

[9]. Sheldon Jr AT. Antiseptic "resistance": real or perceived threat?. Clinical infectious diseases. 2005 Jun 1;40(11):1650-6. doi.org/10.1086/430063

[10]. Vertes A, Hitchins V, Phillips KS. Analytical challenges of microbial biofilms on medical devices. dx.doi.org/10.1021/ac2029997

[11]. Costerton JW. Introduction to biofilm. International journal of antimicrobial agents. 1999 May 1;11(3-4):217-21. DOI: 10.1016/so924-8579(99)ooo18-7 PMID: 10394973.

[12]. Percival SL, Suleman L, Vuotto C, Donelli G. Healthcare-associated infections, medical devices and biofilms: risk, tolerance and control. Journal of medical microbiology. 2015 Apr 1;64(4):323-34.

[13]. Leaper D, McBain AJ, Kramer A, Assadian O, Sanchez JL, Lumio J, Kiernan M. Healthcare associated infection: novel strategies and antimicrobial implants to prevent surgical site infection. The Annals of The Royal College of Surgeons of England. 2010 Sep;92(6):453-8.

[14]. Vickery K, Hu H, Jacombs AS, Bradshaw DA, Deva AK. A review of bacterial biofilms and their role in device-associated infection. Healthcare infection. 2013 Jun 11;18(2):61-6.

[15]. Hall-Stoodley, Luanne, and Paul Stoodley. "Evolving concepts in biofilm infections." Cellular microbiology 11, no. 7 (2009): 1034-1043. doi:10.1111/j.1462-5822.2009. 01323. x

[16] Flemming, Hans-Curt, and Jost Wingender. "The biofilm matrix." Nature reviews microbiology 8, no. 9 (2010): 623-633. doi:10.1038/nrmicro2415

[17] Neu, Thomas R. "The challenge to analyse extracellular polymers in biofilms." In Microbial Mats, pp. 221-227. Springer, Berlin, Heidelberg, 1994.

[18] Flemming, H-C., and Jost Wingender. "Relevance of microbial extracellular polymeric substances (EPSs)-Part I: Structural and ecological aspects." Water science and technology 43, no. 6 (2001): 1-8. DOI: 10.2166/wst.2001.0326

[19] Lembre, Pierre, Cécile Lorentz, and Patrick Di Martino. "Exopolysaccharides of the biofilm matrix: a complex biophysical world." The complex world of polysaccharides (2012): 371-392.doi: $10.5772 / 5213$. 
[20] Sutherland, Ian W. "Biofilm exopolysaccharides: a strong and sticky framework." Microbiology 147, no. 1 (2001): 3-9. doi: 10.1099/00221287-147-1-3.

**[21] Flemming, Hans-Curt, Jost Wingender, T. Griegbe, and Christian Mayer. "Physico-chemical properties of biofilms." Biofilms: recent advances in their study and control. Amsterdam: Harwood Academic Publishers (200o): 19-34. ISBN: 9789058230935.

[22] Davey, Mary Ellen, and George A. O'toole. "Microbial biofilms: from ecology to molecular genetics." Microbiology and molecular biology reviews 64, no. 4 (2000): 847-867. doi: 10.1128/mmbr.64.4.847-867.2000

[23] Dogsa, Iztok, Mojca Brloznik, David Stopar, and Ines Mandic-Mulec. "Exopolymer diversity and the role of levan in Bacillus subtilis biofilms." PloS one 8, no. 4 (2013): e62044. doi.org/10.1371/journal.pone.0062044

[24]. Hlady V, Buijs J. Protein adsorption on solid surfaces. Current Opinion in Biotechnology. 1996 Feb 1;7(1):72-7. doi: 10.1016/s0958-1669(96)80098-X

[25]. Schmidt DR, Waldeck H, Kao WJ. Protein adsorption to biomaterials in Biological interactions on materials surfaces 2009 (pp. 1-18). Springer, New York, NY. DOI 10.1007/978-0-387-98161-1

[26]. Busscher HJ, van der Mei HC, Subbiahdoss G, Jutte PC, van den Dungen JJ, Zaat SA, Schultz MJ, Grainger DW. Biomaterial-associated infection: locating the finish line in the race for the surface. Science translational medicine. 2012 Sep 26;4(153):153rvio-.doi: 10.1126/scitranslmed.3004528

[27]. An YH, Stuart GW, McDowell SJ, McDaniel SE, Kang Q, Friedman RJ. Prevention of bacterial adherence to implant surfaces with a crosslinked albumin coating in vitro. Journal of orthopaedic research. 1996 Sep;14(5):846-9. doi: 10.1002/jor.1100140526.

[28]. Sinha, S. Dutta, Susmita Chatterjee, P. K. Maiti, S. Tarafdar, and S. P. Moulik. "Evaluation of the role of substrate and albumin on Pseudomonas aeruginosa biofilm morphology through FESEM and FTIR studies on polymeric biomaterials." Progress in biomaterials 6, no. 1-2 (2017): 27-38. doi:10.1002/bit.20917.

[29]. De Gennes PG. Wetting: statics and dynamics. Reviews of modern physics. 1985 Jul 1;57(3):827. DOI: doi. org/10.1103/RevModPhys.57.827

[30]. Choudhuri, Madhumita, AN Sekar Iyengar, Alokmay Datta, and M. S. Janaki. "Evolution of self-organized two-dimensional patterns of nanoclusters through demixing." Physical Review E 92, no. 3 (2015): 032907. doi: 10.1103/PhysRevE.92.032907

[31]. Choudhuri, Madhumita, and Alokmay Datta. "Time-structuring in the evolution of 2D nanopatterns through interactions with substrate." Soft Matter 12, no. 27 (2016): 5867-5875. DOI: 10.1039/c6smoo814c. 
[32]. Choudhuri, Madhumita, and Alokmay Datta. "Chain-length dependence of lipophilic force: comparison with the two-body van der Waals' force." Journal of Physics: Condensed Matter 30, no. 35 (2018): 355002. doi:10.1088/1361-648X/aad4b6

[33]. Choudhuri, M., and A. Datta. "Paths to lowering critical point in a two-dimensional orderdisorder transition by Au nanoparticle 'decoration'." Bulletin of Materials Science 43, no. 1 (2020): 18.doi: 10.1007/s12034-020-2058-z

[34]. Ivleva, Natalia P., Michael Wagner, Harald Horn, Reinhard Niessner, and Christoph Haisch. "In situ surface-enhanced Raman scattering analysis of biofilm." Analytical chemistry 80, no. 22 (2008): 8538-8544. DOI: 10.1002/jbio.201000025.

[35]. Leopold, Nicolae, and Bernhard Lendl. "A new method for fast preparation of highly surfaceenhanced Raman scattering (SERS) active silver colloids at room temperature by reduction of silver nitrate with hydroxylamine hydrochloride." The Journal of Physical Chemistry B 107, no. 24 (2003): 5723-5727. doi:10.1021/jpo2746ou.

[36]. Jarvis, Roger M., Alan Brooker, and Royston Goodacre. "Surface-enhanced Raman spectroscopy for bacterial discrimination utilizing a scanning electron microscope with a Raman spectroscopy interface." Analytical Chemistry 76, no. 17 (2004): 5198-5202. DOI: 10.1021/aco49663f

[37]. Ivleva, Natalia P., Michael Wagner, Agathe Szkola, Harald Horn, Reinhard Niessner, and Christoph Haisch. "Label-free in situ SERS imaging of biofilms." The journal of physical chemistry $B$ 114, no. 31 (2010): 10184-10194. doi: 10.1021/jp102466c. 


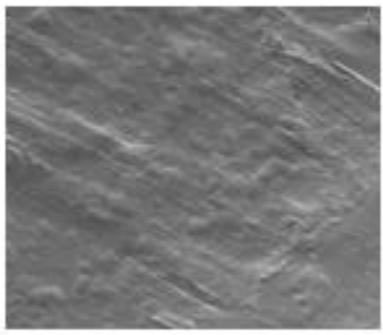

(a)

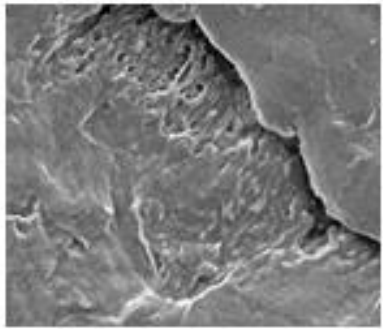

(b)

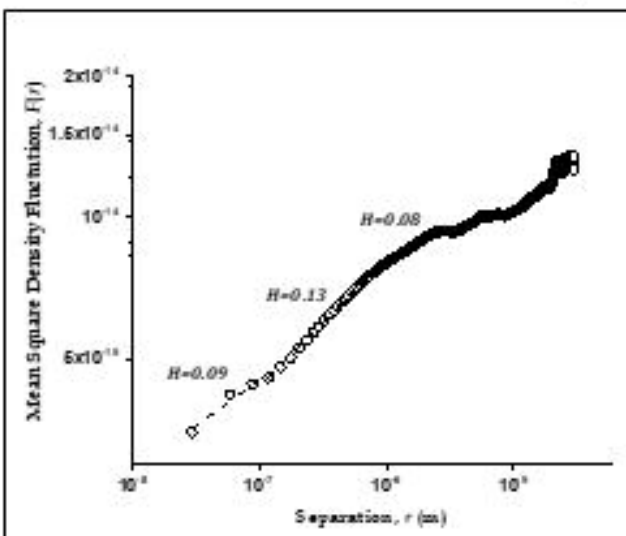

(e)

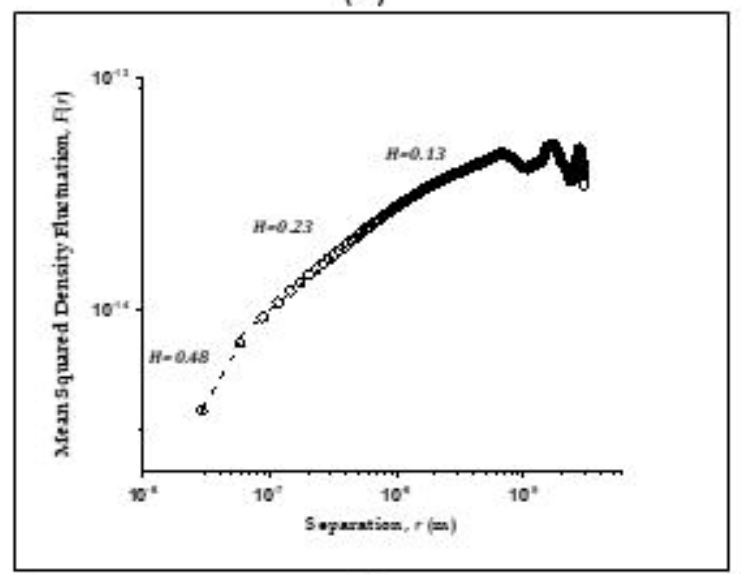

(g)

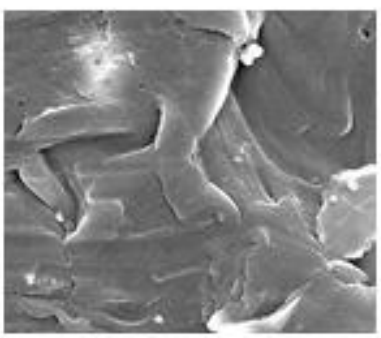

(c)

(d)

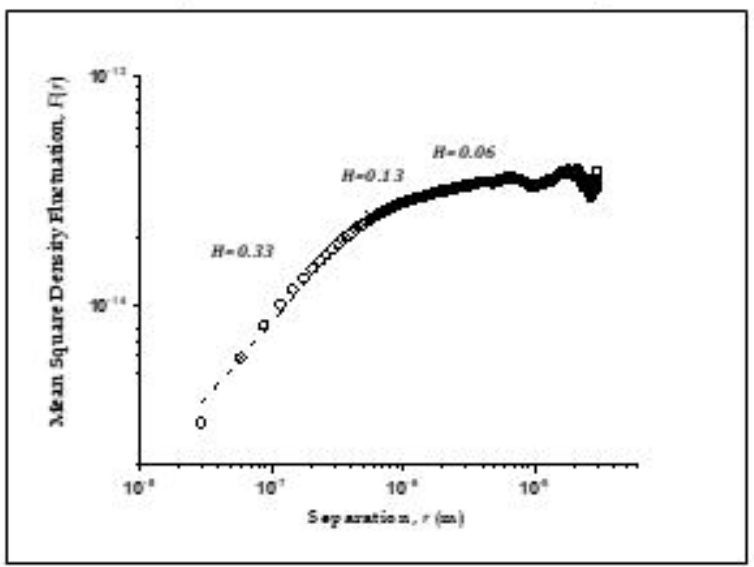

(f)

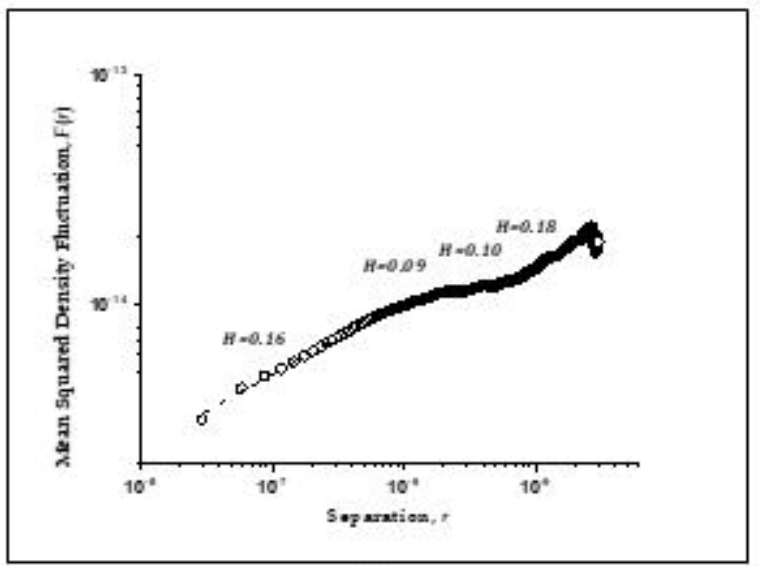

(h) 


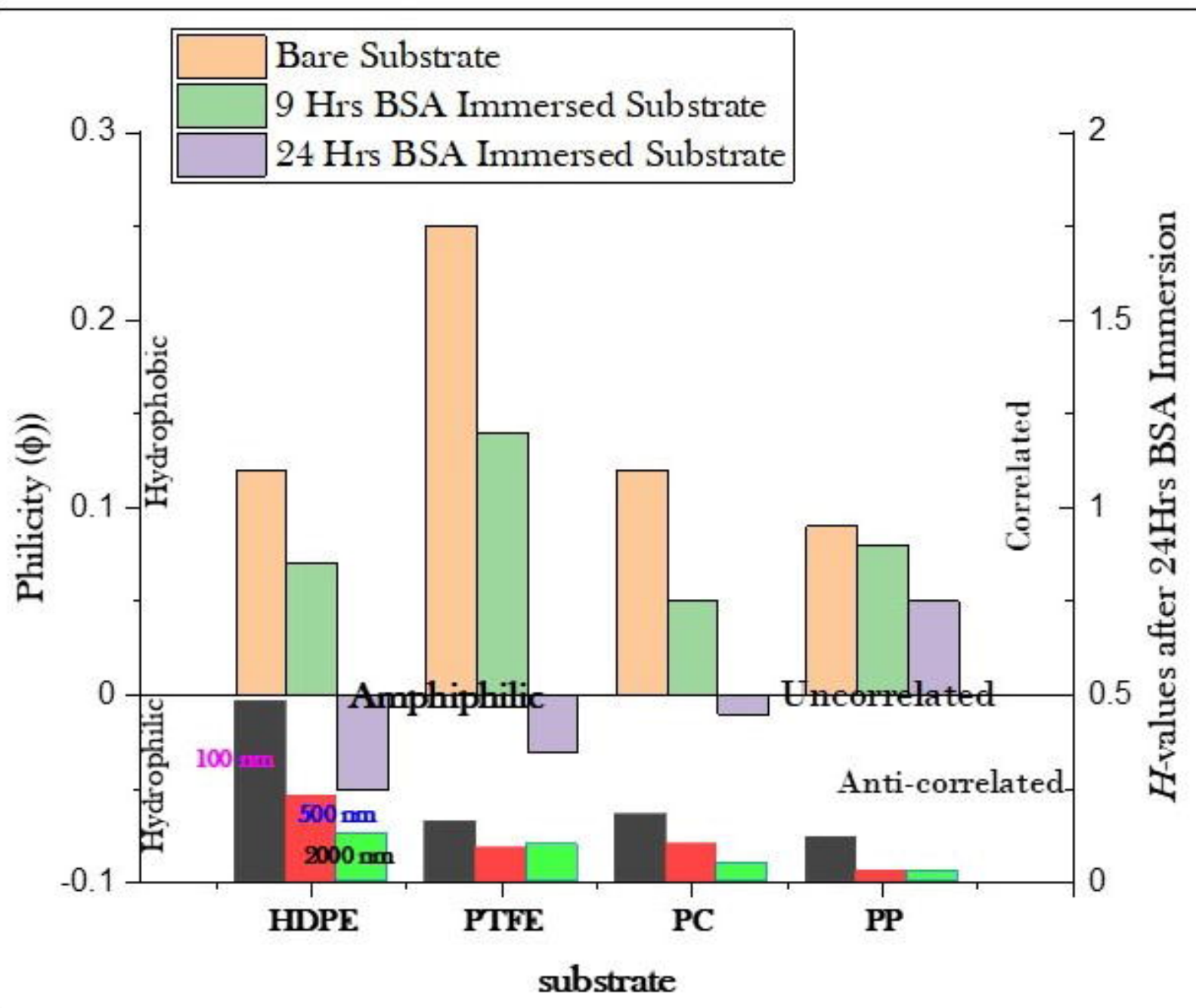




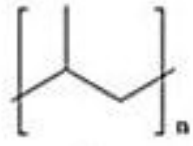

a)

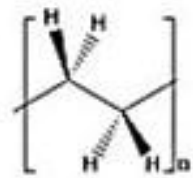

b)

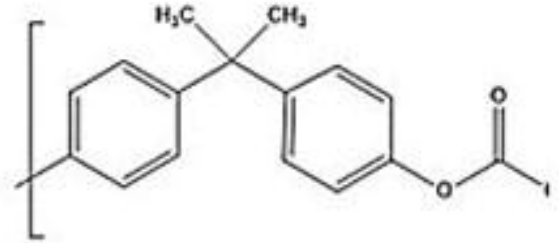

d)
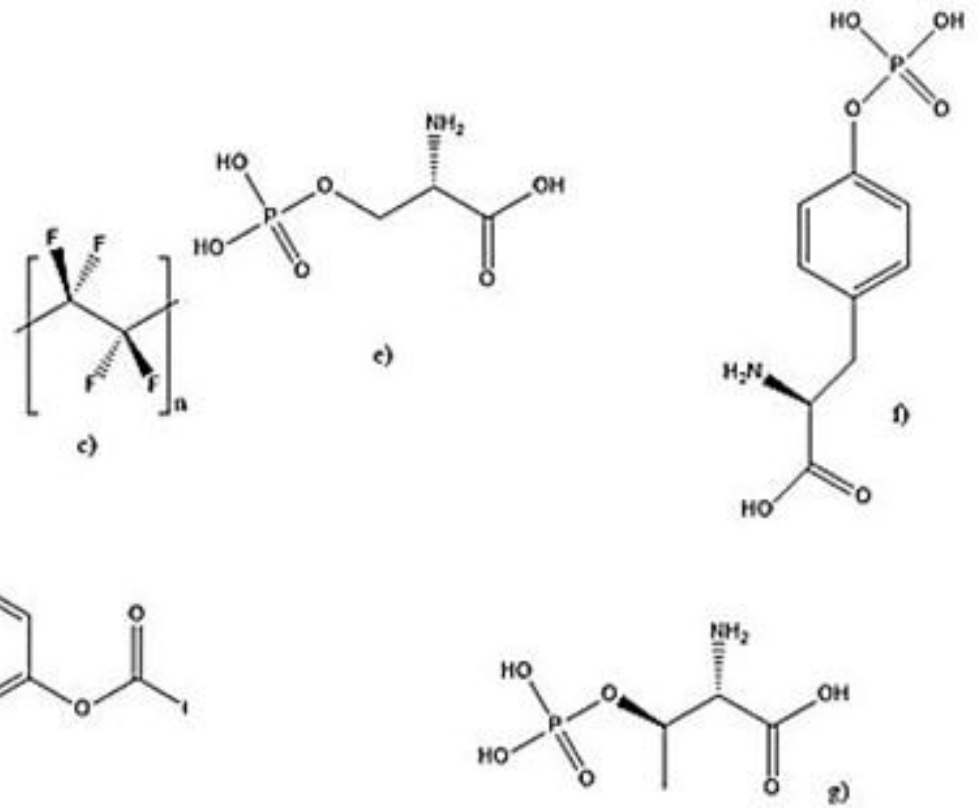


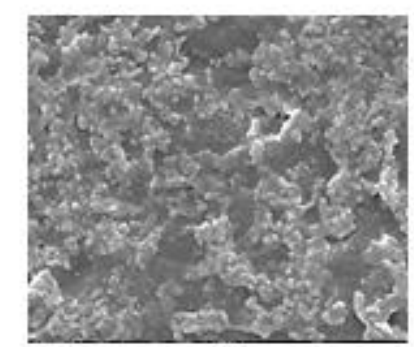

(a)

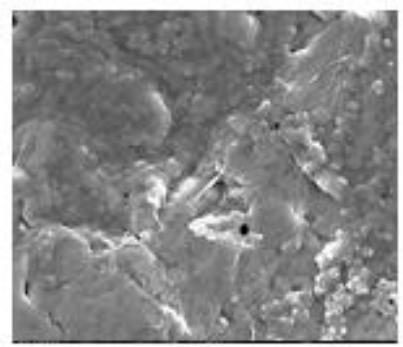

(b)

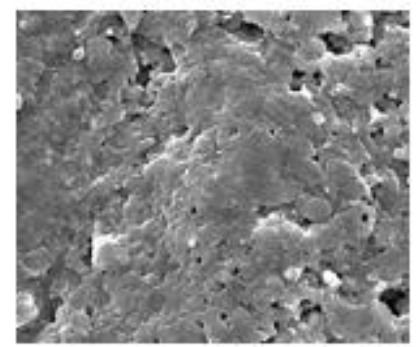

(c)

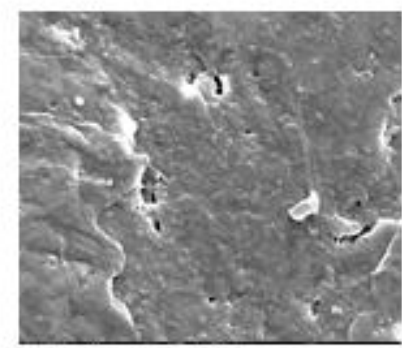

(d)

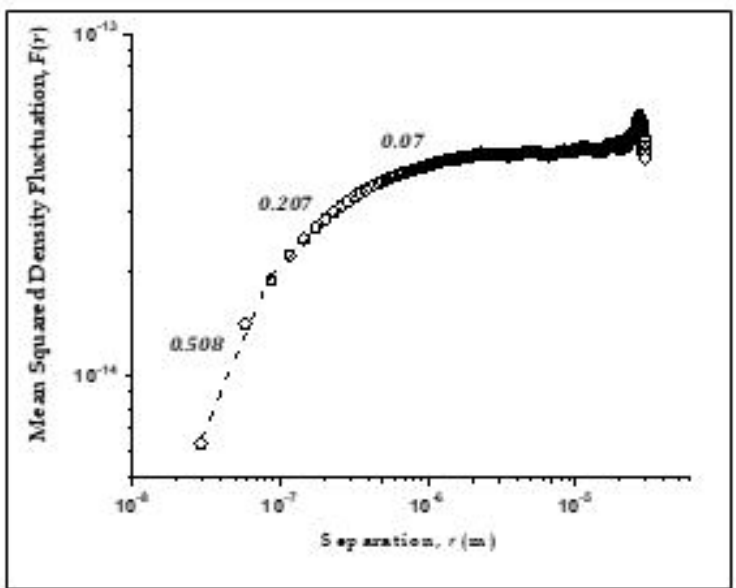

(e)

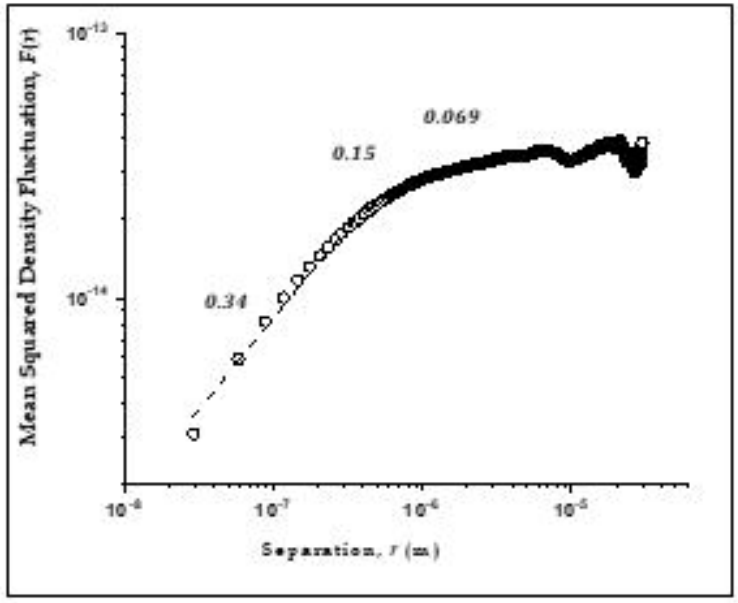

(g)

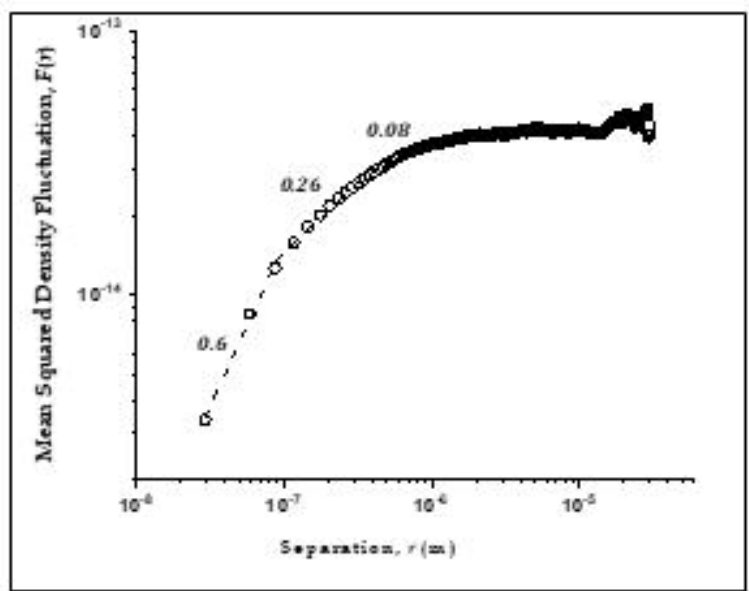

(f)

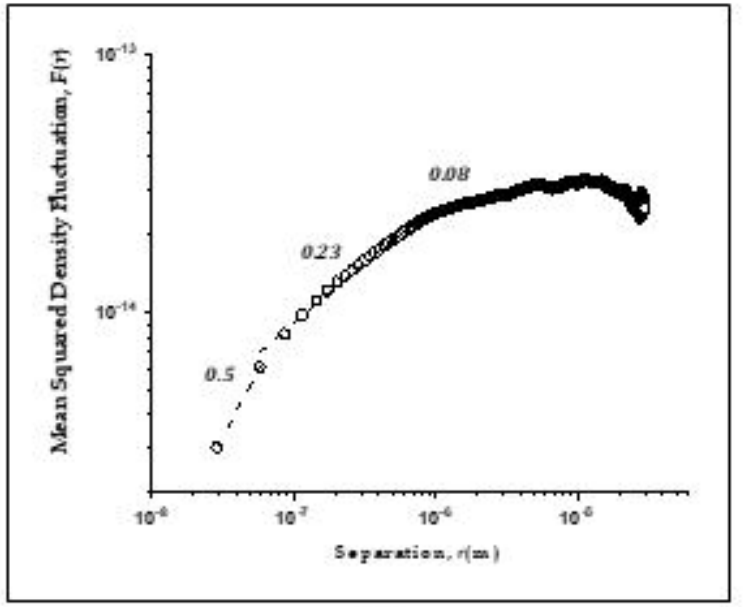

(h) 


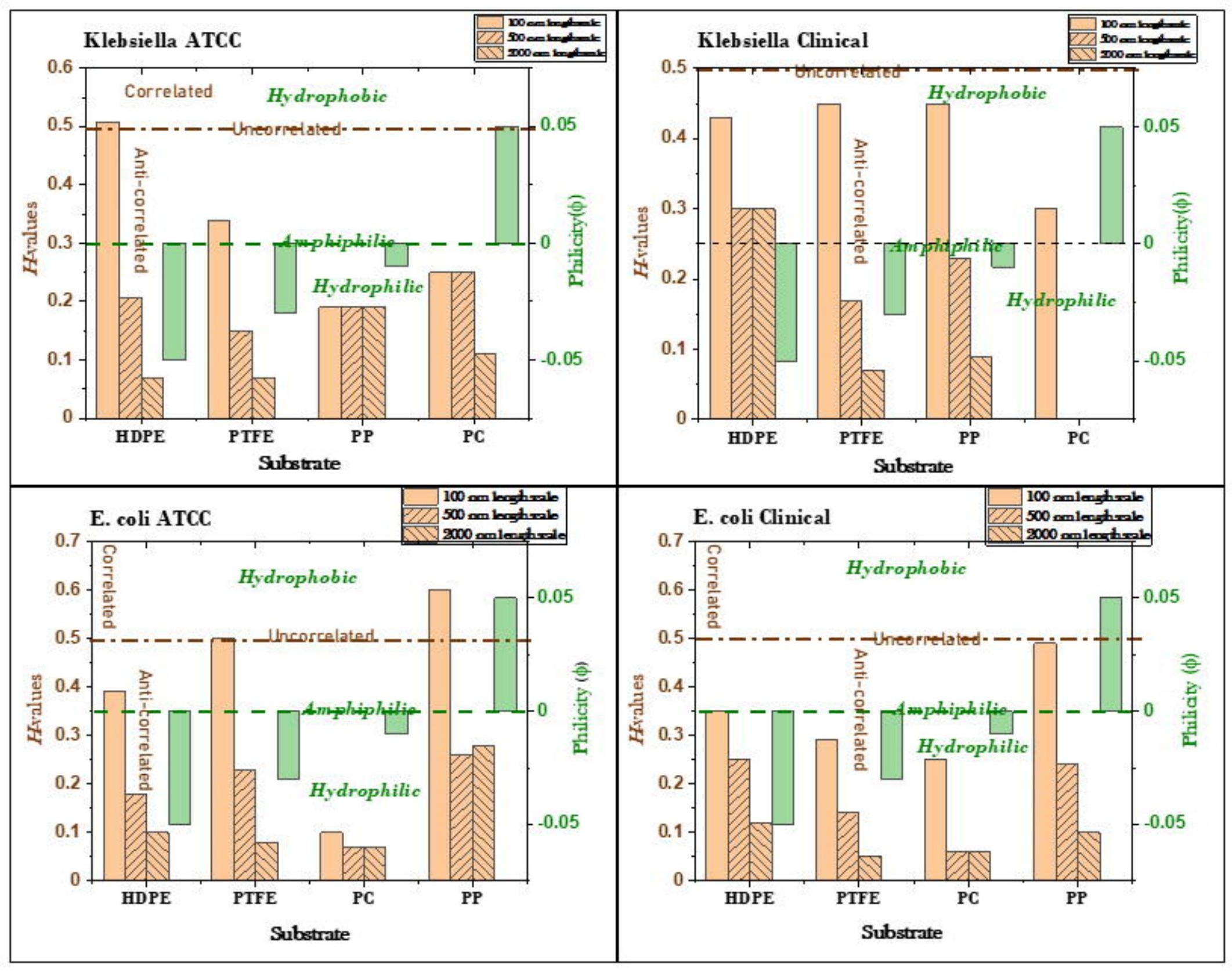




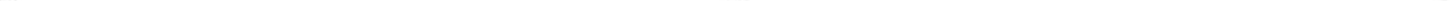


